\title{
Development of Randomized Trials in Adults with Medulloblastoma-The Example of EORTC 1634-BTG/NOA-23
}

\author{
Peter Hau ${ }^{1,2, *}$ (), Didier Frappaz ${ }^{3}$, Elizabeth Hovey ${ }^{4,5}$, Martin G. McCabe ${ }^{6}{ }^{\oplus}$, Kristian W. Pajtler ${ }^{7,8}$, \\ Benedikt Wiestler ${ }^{9}{ }^{(1)}$, Clemens Seidel ${ }^{10}$, Stephanie E. Combs ${ }^{11}$, Linda Dirven ${ }^{12,13}$, Martin Klein ${ }^{14,15}$, \\ Antoinette Anazodo ${ }^{5,16,17} \mathbb{1}$, Elke Hattingen ${ }^{18}\left(\mathbb{D}\right.$, Silvia Hofer ${ }^{19}$, Stefan M. Pfister ${ }^{7,8}$, Claus Zimmer ${ }^{9}$, \\ Rolf-Dieter Kortmann ${ }^{10}$, Marie-Pierre Sunyach ${ }^{20}$, Ronan Tanguy ${ }^{20}$, Rachel Effeney ${ }^{21}$, Andreas von Deimling ${ }^{22,23}$, \\ Felix Sahm ${ }^{22,23}$, Stefan Rutkowski ${ }^{24}$, Anna S. Berghoff ${ }^{25}$, Enrico Franceschi ${ }^{26}{ }^{1}$, Estela Pineda ${ }^{27}$, \\ Dagmar Beier ${ }^{28}\left(\mathbb{D}\right.$, Ellen Peeters ${ }^{29}$, Thierry Gorlia ${ }^{29}$, Maureen Vanlancker ${ }^{29}$, Jacoline E. C. Bromberg ${ }^{30}$, \\ Julien Gautier ${ }^{31}$, David S. Ziegler ${ }^{16,17,32} \mathbb{D}^{-}$, Matthias Preusser ${ }^{25}$, Wolfgang Wick ${ }^{33,34}$ and Michael Weller ${ }^{19}$
}

check for

updates

Citation: Hau, P.; Frappaz, D.; Hovey, E.; McCabe, M.G.; Pajtler, K.W.; Wiestler, B.; Seidel, C.; Combs, S.E.; Dirven, L.; Klein, M.; et al. Development of Randomized Trials in Adults with MedulloblastomaThe Example of EORTC 1634-BTG/ NOA-23. Cancers 2021, 13, 3451. https://doi.org/10.3390/cancers 13143451

Academic Editor: Sheila K. Singh

Received: 16 June 2021

Accepted: 8 July 2021

Published: 9 July 2021

Publisher's Note: MDPI stays neutral with regard to jurisdictional claims in published maps and institutional affiliations.

Copyright: (C) 2021 by the authors Licensee MDPI, Basel, Switzerland. This article is an open access article distributed under the terms and conditions of the Creative Commons Attribution (CC BY) license (https:// creativecommons.org/licenses/by/ $4.0 /)$.
Wilhelm Sander-NeuroOncology Unit, Regensburg University Hospital, 93053 Regensburg, Germany Department of Neurology, Regensburg University Hospital, 93053 Regensburg, Germany Neuro-Oncology Unit, Centre Léon Bérard, 69008 Lyon, France; Didier.Frappaz@ihope.fr Department of Medical Oncology, Sydney 2052, Australia; Elizabeth.Hovey@health.nsw.gov.au

5 Nelune Comprehensive Cancer Centre, Prince of Wales Cancer Centre, Sydney 2031, Australia; Antoinette.Anazodo@health.nsw.gov.au

6 Faculty of Medicine, Biology and Health, University of Manchester, Manchester Academic Health Science Centre, Manchester M20 4GJ, UK; Martin.McCabe@manchester.ac.uk

7 Hopp-Children's Cancer Center Heidelberg (KiTZ), Division of Pediatric Neurooncology, German Cancer Research Center (DKFZ), 69120 Heidelberg, Germany; K.Pajtler@kitz-heidelberg.de (K.W.P.);

S.Pfister@kitz-heidelberg.de (S.M.P.)

8 Department of Pediatric Hematology and Oncology, Heidelberg University Hospital, 69120 Heidelberg, Germany

9 Department of Diagnostic and Interventional Neuroradiology, Klinikum Rechts der Isar der Technischen Universität München, TUM School of Medicine, 81675 Munich, Germany; B.Wiestler@tum.de (B.W.); Claus.Zimmer@tum.de (C.Z.)

10 Department of Radiation-Oncology, University Hospital Leipzig, 04103 Leipzig, Germany; Clemens.Seidel@medizin.uni-leipzig.de (C.S.); Rolf-Dieter.Kortmann@medizin.uni-leipzig.de (R.-D.K.)

11 Department of Radiation Oncology, Klinikum Rechts der Isar der Technischen Universität München, TUM School of Medicine, 81675 Munich, Germany; Stephanie.Combs@tum.de

12 Department of Neurology, Leiden University Medical Center, 2300 RC Leiden, The Netherlands; L.Dirven@lumc.nl

13 Department of Neurology, Haaglanden Medical Center, 2501 CK The Hague, The Netherlands

14 Department of Medical Psychology, Amsterdam UMC, Vrije Universiteit Amsterdam, 1081 HV Amsterdam, The Netherlands; M.Klein@amsterdamumc.nl

15 Brain Tumor Center Amsterdam at Amsterdam UMC, Vrije Universiteit Amsterdam, 1081 HV Amsterdam, The Netherlands

16 Kids Cancer Centre, Sydney Children's Hospital, Sydney 2031, Australia; D.Ziegler@unsw.edu.au

17 School of Women's and Children's Health, University of New South Wales, Sydney 2031, Australia

18 Department of Neuroradiology, University Hospital Frankfurt, Goethe University, 60528 Frankfurt, Germany; Elke.Hattingen@kgu.de

19 Department of Neurology, University Hospital Zurich, 8091 Zurich, Switzerland; silvia.hofer@usz.ch (S.H.); Michael.Weller@usz.ch (M.W.)

20 Department of Radiation Oncology, Centre Leon Berard, 69008 Lyon, France; Marie-Pierre.Sunyach@lyon.unicancer.fr (M.-P.S.); Ronan.Tanguy@lyon.unicancer.fr (R.T.)

21 Department of Radiation Oncology, Royal Brisbane and Women's Hospital, Brisbane 4029, Australia; Rachel.Effeney@health.qld.gov.au

22 Department of Neuropathology, University Hospital Heidelberg, 69120 Heidelberg, Germany; Andreas.vonDeimling@med.uni-heidelberg.de (A.v.D.); Felix.Sahm@med.uni-heidelberg.de (F.S.)

23 Clinical Cooperation Unit Neuropathology, German Consortium for Translational Cancer Research (DKTK), German Cancer Research, 69120 Heidelberg, Germany

24 Department of Pediatric Hematology and Oncology, University Medical Center Hamburg-Eppendorf, 20246 Hamburg, Germany; S.Rutkowski@uke.de

25 Division of Oncology, Department of Medicine I, Medical University of Vienna, 1090 Vienna, Austria; Anna.Berghoff@meduniwien.ac.at (A.S.B.); Matthias.Preusser@meduniwien.ac.at (M.P.) 
26 Medical Oncology Department, Azienda USL/IRCCS Institute of Neurological Sciences, 40139 Bologna, Italy; Enricofra@yahoo.it

27 Barcelona Translational Genomics and Targeted Therapeutics in Solid Tumors Group, Department of Medical Oncology, Hospital Clinic Barcelona, 08036 Barcelona, Spain; Epineda@clinic.cat

28 Department of Neurology, Odense University Hospital, DK-5000 Odense, Denmark; Dagmar.beier@rsyd.dk

29 EORTC Headquarters, 1200 Brussels, Belgium; Ellen.Peeters@eortc.be (E.P.); Thierry.Gorlia@eortc.be (T.G.); Maureen.Vanlancker@eortc.be (M.V.)

30 Erasmus Medical Center Cancer Institute, Department of Neuro-Oncology, 3015 GD Rotterdam, The Netherlands; j.bromberg@erasmusmc.nl

31 Clinical Research Department, Centre Léon Bérard, 69008 Lyon, France; Julien.Gautier@lyon.unicancer.fr

32 Children's Cancer Institute, University of New South Wales, Sydney 2031, Australia

33 Department of Neurology, University Hospital Heidelberg, 69120 Heidelberg, Germany; Wolfgang.Wick@med.uni-heidelberg.de

34 Clinical Cooperation Unit Neuro-Oncology, German Consortium for Translational Cancer Research (DKTK), German Cancer Research, 69120 Heidelberg, Germany

* Correspondence: Peter.Hau@ukr.de; Tel.: +49-941-944-18750

Simple Summary: Medulloblastoma is rare after puberty. Among several molecular subgroups that have been described, the sonic hedgehog $(\mathrm{SHH})$ subgroup is highly overrepresented in the postpubertal population and can be targeted with smoothened (SMO) inhibitors. However, no practicechanging prospective clinical trials have been published in adults to date. Tumors often recur, and treatment toxicity is relevant. Thus, the EORTC 1634-BTG/NOA-23 trial for post-pubertal patients with standard risk medulloblastoma will aim to increase treatment efficacy and to decrease treatment toxicity. Patients will be randomized between standard-dose vs. reduced-dosed radiotherapy, and SHH-subgroup patients will also be randomized between the SMO inhibitor sonidegib (Odomzo ${ }^{\mathrm{TM}}$, Sun Pharmaceuticals Industries, Inc., New York, USA) in addition to standard radio-chemotherapy vs. standard radio-chemotherapy alone. In ancillary studies, we will investigate tumor tissue, blood and cerebrospinal fluid samples, magnetic resonance images, and radiotherapy plans to gain information that may improve future treatment. Patients will also be monitored long-term for late side effects of therapy, health-related quality of life, cognitive function, social and professional live outcomes, and reproduction and fertility. In summary, EORTC 1634-BTG/NOA-23 is a unique multi-national effort that will help to council patients and clinical scientists for the appropriate design of treatments and future clinical trials for post-pubertal patients with medulloblastoma.

Abstract: Medulloblastoma is a rare brain malignancy. Patients after puberty are rare and bear an intermediate prognosis. Standard treatment consists of maximal resection plus radio-chemotherapy. Treatment toxicity is high and produces disabling long-term side effects. The sonic hedgehog (SHH) subgroup is highly overrepresented in the post-pubertal and adult population and can be targeted by smoothened (SMO) inhibitors. No practice-changing prospective randomized data have been generated in adults. The EORTC 1634-BTG/NOA-23 trial will randomize patients between standarddose vs. reduced-dosed craniospinal radiotherapy and $\mathrm{SHH}$-subgroup patients between the SMO inhibitor sonidegib (Odomzo ${ }^{\mathrm{TM}}$, Sun Pharmaceuticals Industries, Inc., New York, USA) in addition to standard radio-chemotherapy vs. standard radio-chemotherapy alone to improve outcomes in view of decreased radiotherapy-related toxicity and increased efficacy. We will further investigate tumor tissue, blood, and cerebrospinal fluid as well as magnetic resonance imaging and radiotherapy plans to generate information that helps to further improve treatment outcomes. Given that treatment side effects typically occur late, long-term follow-up will monitor classic side effects of therapy, but also health-related quality of life, cognition, social and professional outcome, and reproduction and fertility. In summary, we will generate unprecedented data that will be translated into treatment changes in post-pubertal patients with medulloblastoma and will help to design future clinical trials.

Keywords: medulloblastoma; adult; clinical trial; randomized; subgrouping; cerebrospinal fluid; magnetic resonance imaging; radiotherapy; chemotherapy; targeted therapy 


\section{Introduction}

Medulloblastoma is a rare condition in adult neuro-oncology practice [1]. Around 70\% of cases occur in patients under 15 years of age, and the peak incidence is around 5 years of age [2]. The US registry analysis from the Surveillance, Epidemiology, and End Results (SEER) database reported that the incidence of medulloblastoma was 0.6 cases per million in adults [3]. One can assume that the incidence in Europe is similar to the US, summing up to approximately 450 newly diagnosed patients per year in Europe. In post-pubertal patients, medulloblastoma is equally distributed between sexes [1,4].

A staging system was introduced by Chang et al. in 1969 to describe the extent of tumoral infiltration (T1-T4) and metastases (M0-M4) in medulloblastoma [5]. T-stage likely has a prognostic role in adults [6,7]. Concerning metastasis, M1-M4 is considered high-risk in pediatric patients [8,9]. Whether M1 disease has prognostic value in post-pubertal patients and adults is, however, still a matter of debate.

Depending on genetic subgroups, adult and pediatric medulloblastomas are distinct [10-12], which mandates the development of molecularly adapted treatment strategies. In addition to molecular differences, clinically relevant features clearly differentiate adult from pediatric medulloblastoma. For example, adolescents and adults have a higher incidence of lateral localization of the tumor in the hemispheres of the cerebellum than children $[13,14]$. This localization relates to the known overrepresentation of the SHH subgroup in adults [10]. In addition, and in contrast to children, SHH mutations in adults are at the level of SMO or upstream in the vast majority [15]. While treatment has evolved, based on the results of successive randomized clinical trials, in a step-wise fashion in children, it has never been optimized for post-pubertal patients in a prospective, randomized way [16]. Treatment has therefore been extrapolated from experiences in children, and personalized or molecularly stratified therapies have not been developed in adults. The most common treatment regimen in adults is radiotherapy of the craniospinal axis only or radiotherapy combined with the Packer [17] or Taylor [18] chemotherapy regimen at this time. Furthermore, considering the current associated widespread variation in treatment algorithms both within and between countries, multi-national prospective randomized trials in the post-pubertal and adult population are highly warranted. Such trials will be instrumental in improving treatment guidelines and counseling for the design of future clinical trials in this population [16]. In addition, treatment toxicity is high and often includes declines in neurological function, hearing, and cognition, connected to severe impairments in quality of life and social and professional function [19-23], which also mandates approaches to decrease the detrimental side effects of treatment.

Efficacy data for combined radio-chemotherapy for adult patients with medulloblastoma are scarce. The Packer chemotherapy regimen $[17,24]$ has set the basis for a series of pediatric trials $[23,25,26]$ and has also been used in adults. It consists of craniospinal radiotherapy plus weekly vincristine $1.5 \mathrm{mg} / \mathrm{m}^{2}$ (maximum $2 \mathrm{mg}$ ), followed by a maximum of eight cycles of lomustine $75 \mathrm{mg} / \mathrm{m}^{2}$ and cisplatin $70 \mathrm{mg} / \mathrm{m}^{2}$ on day 1 and vincristine $1.5 \mathrm{mg} / \mathrm{m}^{2}$ (max. $2 \mathrm{mg}$ ) on day 1,8 , and 15 of six weekly cycles. In a retrospectively evaluated cohort of the pediatric HIT-2000 trial, 49 non-metastatic adults who received combined radio-chemotherapy experienced a 4 -year event-free survival of $74 \%$ and OS of $94 \%$ [23]. These and other data constitute the basis for a compiled estimated 3-year progression free-survival in adults of around $73 \%[7,21,23,27]$. Alternative chemotherapy regimens that move away from a purely Packer-based adjuvant chemotherapy in favor of a less toxic alternating cisplatin/cyclophosphamide regimen have not yet been tested in adults.

\section{Classification of Medulloblastoma}

According to the concept of an integrated diagnosis of the current and upcoming WHO classifications of tumors of the CNS, medulloblastoma subgroups must be defined by both histological and molecular/genetic features [28]. All medulloblastoma subgroups correspond to WHO grade 4. The WHO classification of 2016, as well as the upcoming 2021 
classification [28], describes five molecularly defined medulloblastoma subgroups-WNTactivated, SHH-activated/TP53 mutated, SHH-activated/TP53 wild-type, group 3, and group 4-and four histological patterns-classic, desmoplastic/nodular, with extensive nodularity, and large cell/anaplastic. There is no perfect concordance of the genetic and histological subgroups at this time.

Diagnosis can be further refined by DNA sequencing, which reveals exact mutations, with the advantage of informing a clinician regarding the potential suitability of a patient for consideration of targeted therapies in SHH medulloblastoma. In adults, SHH-activated, TP53 wild-type medulloblastomas represent the most frequent subgroup, with around 60 to $70 \%$ of cases [11]. SHH activation is typically caused by mutations of PTCH1 or SMO in most adult cases, coding for central critical cell membrane-associated components of the SHH pathway that are potentially actionable with SMO inhibitors [15]. SHH tumors have similar outcomes in infants (5-year overall survival (OS) rate of $67.3-88.0 \%$ ), children (5-year OS rate of $69.8 \%$ ), and adults (5-year OS rate of $88.5 \%$ ) [12], with differential-and sometimes worse-outcomes for the adult subgroup in the older literature. This is likely associated with a specific biology that leads to desmoplastic histology among SHH tumors in infants. Subgroups of patients with certain germline alterations such as TP53, BRCA2, and PALB2 [29] as well as amplifications of MYC/MYCN [30] bear a worse prognosis. However, germline mutations are less commonly found in adults in comparison to children, and most mutations are somatic in this population [31].

\section{Backbone of Therapeutic Strategy in EORTC 1634-BTG/NOA-23}

\subsection{Resection}

Most patients initially present with hydrocephalus or symptoms from mass effect caused by the tumor. A gross total resection of the primary tumor should therefore be considered in all patients to alleviate symptoms and to facilitate rapid diagnosis [32]. In patients with group 4 tumors, there is an established association between improved progression-free survival and gross total resection. In cases where gross total resection is not safe and/or feasible, a maximal safe resection, sparing eloquent areas and leaving residual tumor behind, should be performed [33]. Best possible resection will therefore be a mainstay of EORTC 1634-BTG/NOA-23 to set the stage for an effective therapy and also to provide sufficient tissue for histological and molecular diagnosis and subgrouping.

\subsection{Radiotherapy}

Radiotherapy is an essential component of the combined modality treatment of medulloblastoma and also the backbone of EORTC 1634-BTG. Given the propensity of medulloblastoma to disseminate via the CSF, EORTC 1634-BTG will follow the current practice in non-infants with confirmed medulloblastoma that consists of craniospinal irradiation (CSI) with a boost to the tumor bed [34].

In pediatric cohorts, the quality of radiotherapy strongly relates to survival and functional outcome. Several reports showed that inadequate treatment had a negative impact on tumor control and survival [35,36]. A more recent analysis of the PNET5 trial underlined the necessity of pretreatment central quality control [37]. Radiotherapy should be initiated within 4-6 weeks after surgery, and the course of radiotherapy should ideally be performed without interruptions $[37,38]$.

Historically, CSI is delivered with a total dose of $36 \mathrm{~Gy}$ in daily fractions of $1.8 \mathrm{~Gy}$, or of $35.2 \mathrm{~Gy}$ in daily fractions of $1.6 \mathrm{~Gy}$, each five times weekly. In addition, a local dose escalation to the posterior fossa or, more recently, tumor bed [39] is performed as a boost treatment. Generally, a total dose up to 54/55.8 Gy should be achieved in the boost region [6]. Since radiotherapy can generate dose-dependent long-term side effects, dose reduction of craniospinal axis radiotherapy has been evaluated in clinical trials in children. A neuroaxis dose reduction from 36 Gy to $23.4 \mathrm{~Gy}$ in combination with chemotherapy has been used in pediatric trials [17] and was equivalent in all published trials. The current PNET5 trial will evaluate if an even lower total CSI dose of 18.0 Gy is 
possible in good prognostic subgroups. The question of radiotherapy dose reduction has not been investigated in a randomized way in adults; however, single-arm data indicate that a dose reduction to $23.4 \mathrm{~Gy}$ is feasible without losing efficacy [40]. A phase III trial for patients up to 21 years of age with standard-risk disease showed that a CSI dose of $23.4 \mathrm{~Gy}$ in 13 fractions with local dose escalation to the tumor bed of $32.4 \mathrm{~Gy}$ in 18 fractions demonstrated similar efficacy to contemporary studies of higher-dose craniospinal radiotherapy [41].

Radiotherapy-related toxicity is of concern, especially in patients with long-term survival, where chronic side effects become relevant. It may include declines in neurocognitive and neuropsychological functioning, social skills, attention, and reading [42-44]. The effect of CSI on cognition is dose-dependent $[45,46]$. Moreover, radiotherapy of the spinal axis may contribute to a risk of gonadal dysfunction and subsequent fertility issues in female patients caused by scatter irradiation. Long-term survivors of childhood medulloblastoma are also at increased risk of secondary tumors, hearing impairment, stroke, poor balance, and cataracts [47]. Of caution, the risk for certain side effects, particularly hematological side effects, is higher in older patients. Therefore, high-precision radiotherapy techniques to spare the vertebrae represent an important issue [48]. Radiotherapy dose reduction with the aim of reducing radiotherapy toxicity will therefore be the most important clinical secondary endpoint of EORTC 1634-BTG. Based on the referenced data, we will adhere to a 35.2 Gy dose to the craniospinal axis in the standard arm, except for patients below age 18, who will receive $23.4 \mathrm{~Gy}$. All patients with M0 disease in the experimental arm will receive a reduced $23.4 \mathrm{~Gy}$ dose to the craniospinal axis. Patients with M1 disease will receive $35.2 \mathrm{~Gy}$.

If available, proton beam therapy can be considered an alternative to helical tomotherapy or volumetric modulated arc therapy (VMAT) to reduce the radiation dose outside of the target volume and therefore reduce the risk of short-term and long-term side effects $[49,50]$. Similar survival outcomes were reached in children with proton compared to photon irradiation [51,52]. However, there are only a few prospective comparisons between photon and proton treatment with regard to short- and long-term toxicity as well as disease outcomes. Proton beam therapy will be encouraged in EORTC 1634-BTG and its safety and efficacy will be investigated as a secondary endpoint in comparison to photon therapy.

\subsection{Combined Radio-Chemotherapy}

Data from recent meta-analyses $[53,54]$ and prospective single-arm trials $[21,23,27,55,56]$ strongly suggest a beneficial role of chemotherapy in addition to radiotherapy in adult patients with medulloblastoma. A recent meta-analysis by Kocakaya et al. analyzed 227 publications with 907 patients. Patients who received chemotherapy first-line survived significantly longer (median OS, mOS: 108 months, 95\% CI: 68.6-148.4) than patients treated with radiotherapy alone (mOS: 57 months, 95\% CI: 39.6-74.4) [53]. In a similar meta-analysis, radio-chemotherapy was associated with a superior mOS compared with radiotherapy alone (HR: 0.53; 95\% CI: 0.32-0.88, $p=0.01$ ) [54].

Prospective single-arm trials in adults and retrospectively evaluated subpopulations from pediatric trials corroborate a survival gain through radio-chemotherapy in comparison to radiotherapy. In a prospective trial by Brandes et al. [55,57], 26 high-risk patients received two cycles of upfront chemotherapy, either with a MOPP-like regimen or with cisplatin, etoposide, and cyclophosphamide, followed by radiotherapy and maintenance chemotherapy. After a median follow-up of 7.6 years, the overall PFS and OS rates at 5 years were $72 \%$ and $75 \%$, respectively. A further analysis of this trial with a median follow-up of 10 years showed that low-risk patients who had received cisplatin-based chemotherapy after radiotherapy obtained 5-year and 10-year OS rates of 100\%, compared to 5 -year and 10 -year OS rates of $100 \%$ and $78.6 \%$ in patients treated with radiotherapy alone [7,27]. The HIT-2000 trial generated an adult observational cohort of 49 patients with non-metastatic disease patients who received combined radio-chemotherapy with eight doses of vincristine $1.5 \mathrm{mg} / \mathrm{m}^{2}$ (maximum $2 \mathrm{mg}$ ) during radiotherapy, followed 
by a maximum of eight cycles of lomustine $75 \mathrm{mg} / \mathrm{m}^{2}$ day 1 , cisplatin $70 \mathrm{mg} / \mathrm{m}^{2}$ day 1 , and vincristine $1.5 \mathrm{mg} / \mathrm{m}^{2}$ (max. $2 \mathrm{mg}$ ) on day 1,8 , and 15 of six-weekly cycles and experienced a 4-year event-free survival rate of $74 \%$ and overall survival rate of $94 \%$ [23]. This regimen has been prospectively evaluated with regard to toxicity aspects within the NOA-07 trial [21]. In NOA-07, toxicity was moderate, with $70 \%$ of patients tolerating at least four cycles of chemotherapy, all of them with dose modifications. Feasibility appeared to be age-dependent, leading to the application of four cycles of chemotherapy in $72.7 \%$ of patients below age 45 and $62.5 \%$ of patients aged 45 or above $(p=0.66)$. Assessing for the specific outcome of completion of all eight maintenance cycles demonstrated that $45.5 \%$ of all patients younger than 45 years completed eight cycles, whereas only $12.5 \%$ of patients over 45 years received all cycles $(p=0.199)$. Severe adverse events were significantly more frequent in patients older than 45 years of age $(p=0.040)$. No treatment-related deaths were observed. Leukopenia was the major toxicity. Polyneuropathy and ototoxicity were the only grade 3 and 4 non-hematological toxicities [21].

A combined view on the efficacy and tolerable toxicity of all previously used options in the adult setting led to the selection of NOA-07 (HIT-2000, Packer) as the suitable radiochemotherapy regimen for the standard arm of a prospective trial in post-pubertal and adult patients with medulloblastoma. Based on published data, we concluded that lowering the dosing frequency of vincristine to every second week and the number of maintenance cycles to six would allow clinicians to treat more than $50 \%$ of patients with the full regimen and acceptable resultant toxicity. As we intend to adhere as much as possible to published data, we will not eliminate vincristine from the chemotherapy regimen. Additionally, carboplatin might be a pragmatic substitute for cisplatin, based on its more favorable toxicity profile $[23,58]$. However, no published data thus far have systematically replaced cisplatin by carboplatin in adults, and it is therefore deemed not justified to routinely replace cisplatin with carboplatin in the EORTC 1634-BTG/NOA-23 trial. However, if cisplatin-related side effects occur, investigators will be free to substitute cisplatin by carboplatin. Strict tapering and stopping rules will apply that will allow early and fast de-escalation and discontinuation of the drugs used in EORTC 1634-BTG/NOA-23, if presumptively related symptoms occur.

\subsection{Targeted Therapy}

Medulloblastoma is well understood on a molecular level, and two of the molecular subgroups, $\mathrm{SHH}$ and WNT, are driven by pivotal signaling pathways that are, in principle, amenable to targeted therapies $[59,60]$. A series of clinical trials have been initiated that target specific molecular subgroups of medulloblastoma [61,62].

At this point, the sonic hedgehog ( $\mathrm{SHH}$ ) subgroup is the population of choice for a personalized targeted intervention in adults with medulloblastoma, as this subgroup constitutes the majority of adult patients (60-70\%) [11,63], and specific inhibitors of smoothened (SMO), an upstream member of the SHH signaling pathway, are available. In addition, the use of SMO inhibition as a mechanism to reduce SHH pathway activation holds excellent biological rationale, as adult patients within the $\mathrm{SHH}$ subgroup have a very low frequency of mutations downstream of SMO [10,15].

Animal model data [64] and non-randomized trials in patients with SHH-driven tumors $[65,66]$ generated impressive results. An activated hedgehog pathway predicts response to SMO inhibition in these tumors [67]. Sonidegib is a potent oral SMO inhibitor, which showed efficacy in patients with solid tumors [68] and was evaluated in a phase II (ClinicalTrials.gov: NCT01125800, 26 May 2020) and a phase III trial (ClinicalTrials.gov: NCT01708174, 26 May 2020) in pediatric and adult patients with medulloblastoma [69]. One of the reasons for low recruitment in these trials was that SMO inhibitors induce premature growth plate fusions in children [70], a side effect that is fortunately not relevant in post-pubertal patients and therefore not limiting when growth plates have already fused. In the EORTC 1634-BTG/NOA-23 study, only post-pubertal and adult patients will be included, avoiding this problem. The recently published MEVITEM trial evaluated 
vismodegib, another SMO inhibitor, plus temozolomide in immunohistochemically defined, recurrent, SHH-driven adult medulloblastoma. In 10 patients in the combination arm, PFS-6 was $20 \%$ and the overall response rate was $40 \%$ (95\% CI: 12.2; 73.8), and among 11 patients with an expected sensitivity according to next-generation sequencing, three had a partial response and four remained stable. The authors concluded that the prediction of sensitivity to vismodegib needs further refinements [62]. In addition, sensitivity to SMO inhibition is likely lower in this relapsed cohort in comparison to a therapy-naïve cohort due to the genetic divergence between primary and relapsed disease [71]. Of note, sonidegib also seems to be more effective in comparison to vismodegib in patients with medulloblastoma [72].

Data on the pharmacokinetics of sonidegib suggest favorable blood-brain barrier penetration [68,73]. As medulloblastomas are associated with a disrupted blood-brain barrier [74] that correlates to contrast enhancement in MRI [75], sufficient intra-tumoral drug levels can be anticipated. In addition, sonidegib will be given in combination with radiotherapy in EORTC 1634-BTG/NOA-23, which is thought to further disrupt the bloodbrain barrier, at least in the short term [76].

Sonidegib has a favorable toxicity profile with rare haematological toxicities in adults, which is an important point if a combination therapy with classical chemotherapeutics and radiotherapy is considered. The most frequently reported adverse events with combined therapy including sonidegib in 230 patients with basal cell carcinoma were muscle spasms $(54 \%)$, musculoskeletal pain $(32 \%)$, and myalgia $(19 \%)$. Increased serum creatin kinase (CK) laboratory values occurred in $61 \%$ of patients, with $8 \%$ of patients having grade 3 or 4 serum CK elevations [77]. In a pooled safety analysis of 12 clinical studies involving 571 patients with various advanced cancers treated with sonidegib at daily doses ranging from $100 \mathrm{mg}$ to $3000 \mathrm{mg}$, rhabdomyolysis occurred in one patient $(0.2 \%)$ treated with sonidegib $800 \mathrm{mg}$. Other relevant side effects were alopecia, dysgeusia, decreased appetite, nausea, diarrhea, fatigue, abdominal pain, headache, pruritus, and minor effects on bone marrow. Therefore, the treatment-limiting side effects of sonidegib do not overlap with the typical side effects of radiotherapy, besides a possible, but minor, additional toxicity on bone marrow. As CSI and sonidegib have not been investigated in a combined manner yet, a run-in phase will be performed in EORTC 1634-BTG/NOA-23.

\section{Trial Design}

Considering the biological and prognostic diversity of pediatric and adult medulloblastoma $[10,11]$ and the lack of prospective randomized data in adults, there is an unmet medical need to develop efficacious treatment regimens for these patients. This is also true in view of the intermediate to dismal prognosis for post-pubertal and adult medulloblastoma patients, and the considerable toxicity of craniospinal radiotherapy. The EORTC 1634-BTG/NOA-23 trial (ClinicalTrials.gov: NCT04402073, 26 May 2020) is a multicenter, randomized, controlled, open-label, phase II trial open for M0/M1 medulloblastoma. EORTC 1634-BTG/NOA-23 is the first trial worldwide that prospectively enrolls postpubertal and adult patients with medulloblastoma according to their molecular subgroup in a randomized design, with the aim to lower treatment toxicity and increase efficacy in these patients (Figure 1). 


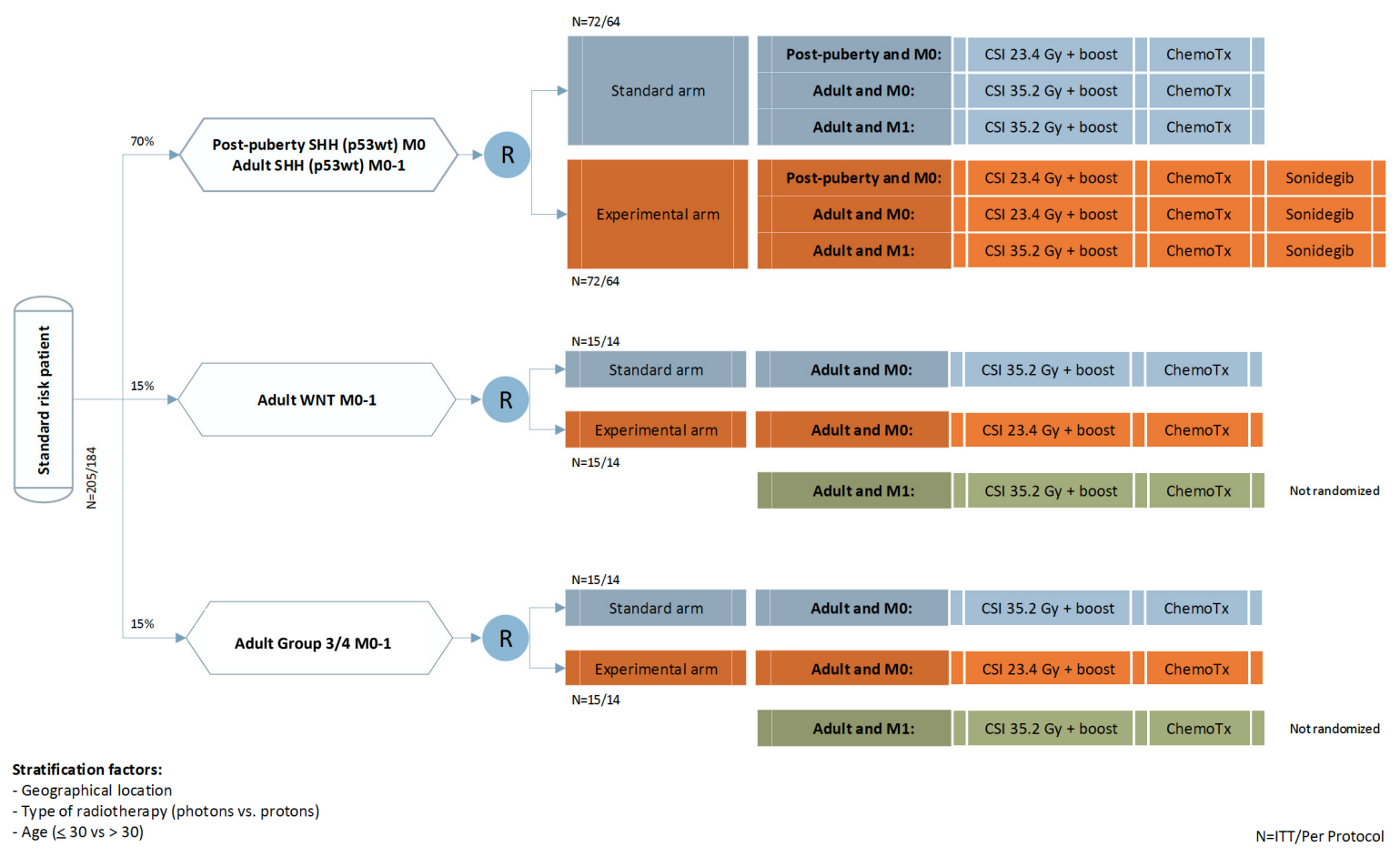

Figure 1. Trial design: Patients will be stratified into their respective genetic subgroups. Randomization will be performed into regular-dose (35.2 Gy) and low-dose (23.4 Gy) radiotherapy for all strata, and radio-chemotherapy vs. reduced radio-chemotherapy plus sonidegib in the $\mathrm{SHH}$ subgroup. Chemotherapy consists of 4 doses of vincristine $1.5 \mathrm{mg} / \mathrm{m}^{2}$ (maximum $2 \mathrm{mg}$ ) during radiotherapy, followed by a maximum of 6 cycles of lomustine $75 \mathrm{mg} / \mathrm{m}^{2}$ on day 1 , cisplatin $70 \mathrm{mg} / \mathrm{m}^{2}$ on day 1 , and vincristine $1.5 \mathrm{mg} / \mathrm{m}^{2}$ (max. $2 \mathrm{mg}$ ) on day 1 and 15 of 6-weekly cycles. The following modification for post-pubertal patients aged 17 and below with WNT and group 3/group 4 will apply: these patients will not be treated in the EORTC 1634-BTG/NOA-23 trial and will be recommended to participate in a suitable pediatric trial. $\mathrm{N}=$ number of patients; $\mathrm{R}=$ randomization; $\mathrm{SHH}, \mathrm{WNT}$, group 3/group 4 are medulloblastoma subgroups; $\mathrm{M}=$ metastasis; $\mathrm{CSI}=$ craniospinal irradiation; Gy = gray; ChemoTx = chemotherapy, ITT = intent to treat. Please note that group 3 patients were not included in the initial version of the protocol, but will be included in the amended version 3.0 as depicted.

The 1634-BTG/NOA-23 trial therefore aims at developing a personalized, genotypebased, intensity-modulated therapy for post-pubertal and adult patients with newly diagnosed medulloblastoma. It will generate a study population with well-annotated clinical data that will be connected to translational subprojects. The translational subprojects will enable us to evaluate molecular, radiomic, and radiogenomic data as well as data on health-related quality of life (HR-QoL), neurocognitive functioning, and fertility and endocrine events to gain deeper insights into subgrouping, risk stratification of adult disease, therapeutic targets, resistance mechanisms, and the toxicity of these treatments.

Patients of all medulloblastoma molecular subgroups will be included in the trial and treated. Adult patients with M1 disease will be included in 1634-BTG/NOA-23, as there are no clear data that M1 disease bears an inferior prognosis in adults [53,58,78].

A radio-chemotherapy backbone will be used in the standard as well as the experimental arm. In the experimental arm, CSI dose will be reduced $[17,24]$ and an SMO inhibitor, sonidegib, will be added for patients with SHH-activated medulloblastoma, based on its biological rationale and published clinical data $[68,69,73]$. Based on the referenced data that suggest equal efficacy of 35 Gy vs. 23.4 Gy CSI doses [17,40,41,79], the reduction of toxicity with dose-reduced CSI while maintaining efficacy will be investigated by using $35.2 \mathrm{~Gy}$ in the standard vs. $24.6 \mathrm{~Gy}$ in the experimental arm of the trial. The EORTC 1634/NOA-23 chemotherapy regimen will consist of four doses of vincristine $1.5 \mathrm{mg} / \mathrm{m}^{2}$ (maximum $2 \mathrm{mg}$ ) during radiotherapy, followed by a maximum of six cycles of lomustine $75 \mathrm{mg} / \mathrm{m}^{2}$ on day 1 , cisplatin $70 \mathrm{mg} / \mathrm{m}^{2}$ on day 1 , and vincristine $1.5 \mathrm{mg} / \mathrm{m}^{2}$ (max. $2 \mathrm{mg}$ ) on day 1 and 15 of six-weekly cycles. Considering that post-pubertal patients with SHH-subgroup 
medulloblastomas are the prime target population for $\mathrm{SHH}$ inhibitors $[15,67]$, an increase in efficacy in the $\mathrm{SHH}$ subgroup will be the primary efficacy endpoint. As no formal combination data of sonidegib with radiotherapy are available at this time, a run-in phase with 10 patients will be included in EORTC 1634-BTG/NOA-23, who will be observed closely for unexpected toxicity.

The EORTC 1634-BTG/NOA-23 trial will be performed in more than 40 sites in Europe and Australia. A list of activated participating sites can be found at https://www. clinicaltrials.gov / ct2/ show / NCT04402073, accessed on 26 May 2020.

\section{Objectives}

The primary objective of 1634-BTG/NOA-23 is to compare progression-free survival of a personalized intensity-modulated therapy (experimental arm; sonidegib) vs. standard therapy in the SHH-dependent subgroup. Secondary objectives include the reduction of radiotherapy toxicity with a dose-reduced CSI while maintaining efficacy and additional efficacy objectives. As patient-reported outcomes are highly important in a setting where young patients in the middle of their lives are affected, short- and long-term health-related quality of life (HR-QoL), neurocognitive function, social outcome, and fertility/endocrine function as well as fertility interventions will be related to these data. Even if the primary objective of the trial should remain negative, the secondary objectives will enable us to better understand the individual value of this risk-stratified personalized therapy approach, which not only bears the chance for enhanced efficacy, but also the risk of enhanced toxicity during the entire disease trajectory.

A number of translational research objectives aim to construct measurable parameters that can predict the clinical outcome of post-pubertal patients with medulloblastoma. This includes a more precise classification of subgroups using molecular data and radio-genomic classifiers, as well as the evaluation of molecular characteristics within the SHH subtype that may explain response patterns, testing of the feasibility of circulating tumor DNA (ctDNA) from cell-free cerebro-spinal fluid (CSF) and blood for molecular subgrouping, detection of minimal residual disease, and detection of new molecular targets, pathway modifiers, and resistance mechanisms in the SHH subgroup. We further will evaluate biomarkers from tumor tissue within the SHH subtype that may explain early side effects and predict radiotherapy toxicity and endocrinology and fertility issues. These translational objectives will also add important information to the design of future trials in medulloblastoma.

\section{Evaluation of Efficacy and Statistics}

Verification of inclusion and exclusion criteria will be done centrally and includes a neuropathology review and molecular subgroup analysis, which classifies patients according to their molecular subgroup (SHH, WNT, group 3, and group 4). Patients will be centrally randomized between the standard and experimental arm. A minimization technique will be used for random treatment allocation stratified by country, type of radiotherapy (proton versus photon), and age ( $\leq 30$ vs. $>30)$ in the SHH subgroup and type of radiotherapy (proton vs. photon) in the WNT, group 3, and group 4 subgroups. $\mathrm{SHH}$-activated patients under age 18 with $\mathrm{M} 1$ disease and patients under age 18 in the WNT-, group 3, and group 4 subgroups will not be enrolled, and will be recommended to participate in the HRMB or PNET5/SIOP trials, depending on their risk profile. Adults with M1 disease in the WNT, group 3, and group 4 subgroups will be enrolled, but not randomized, and will be treated with standard radio-chemotherapy.

The total number of patients to be registered is estimated at 205, including $128 \mathrm{SHH}$ M0-1 eligible patients who started their allocated treatment.

Treatment decisions will be based on the adapted response assessment in pediatric neuro-oncology (RAPNO) criteria [75] as assessed by the local investigator. Imaging will be verified by a central review board at the time point of patient inclusion and suspected 
tumor progression. Response to treatment will be assessed on the basis of an MRI of the brain and spine, CSF cytology, and the neurologic exam.

The evaluation of progression-free survival (PFS) in patients with SHH-subgroup medulloblastoma in comparison of the standard vs. experimental arm will be powered statistically as the primary endpoint. We hypothesize that the addition of sonidegib to the standard treatment will increase the progression-free survival (PFS) rate at 3 years in a statistically significant and clinically meaningful way. A PFS rate at 3 years equal to $86.6 \%$ in the experimental arm (HR, Hazard Ratio, equal to 0.456 ) is considered clinically relevant compared to an expected PFS-3 of $73.0 \%$ in the standard arm for SHH-subgroup patients based on cumulative prior literature $[7,21,23,27]$. We plan to show this difference at one-sided $10 \%$ significance ( $20 \%$ two-sided) and with $90 \%$ power and assume a cumulative drop-out rate at 3 years of $5 \%$ in each treatment arm. Based on these assumptions, 43 PFS events in the standard arm of the SHH subgroup are needed to evaluate the primary endpoint. For the WNT subgroup, group 3, and group 4, differences in PFS between the treatment arms will be assessed in the intent-to-treat patients (ITT) population. Assuming a monthly accrual of 4.26 patients after an activation period of 1 year, 128 eligible patients from the SHH subgroup who started their allocated treatment will be randomized between the standard arm and experimental arm during 36 months and followed-up for 55 months with a total duration of 91 months.

The evaluation of safety in medulloblastoma patients in the SHH, WNT, group 3, and group 4 subgroups in comparison of the standard vs. experimental arm will be performed with descriptive intent only, based on CTCAE criteria.

\section{Translational Research}

Several reference and translational work packages are based on the prospective randomized EORTC-1634/NOA-23 phase II trial. The trial backbone will allow the generation of data and bio- as well as imaging material that will be processed to the reference centers and translational work packages (Figure 2).

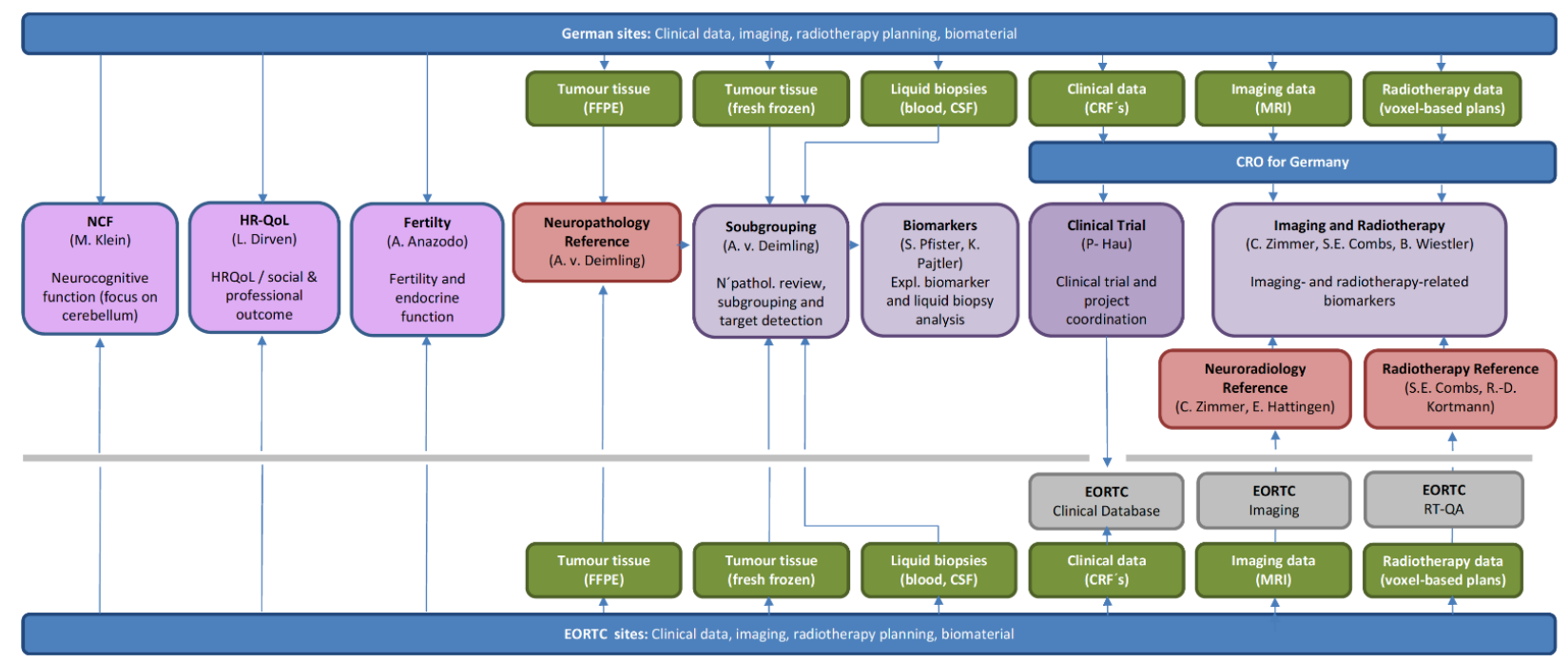

Figure 2. Graphic representation of the overall trial and translational project organization: EORTC is the sponsor of the trial, will host the trial in cooperation with Neuro-Onkologische Arbeitsgemeinschaft in der Deutschen Krebsgesellschaft (NOA), and ensure processing of clinical data, imaging data, and biomaterial that are analyzed within the translational subprojects. Reference sites for neuropathology, neuroimaging, and radiotherapy quality assurance have been defined and will directly receive biomaterial from sites and MRI images and voxel-based radiotherapy plans from the EORTC imaging platform and EORTC quality assurance in radiotherapy (RT-QA) platform. Neuro-cognition (NCF), health-related quality of life (HRQoL), and fertility and endocrine function will be assessed centrally. Responsible sites and principal investigators are named in the respective task boxes. $\mathrm{WP}=$ work package; $\mathrm{FFPE}=$ formalin-fixed paraffin-embedded; $\mathrm{CSF}=$ cerebrospinal fluid; $\mathrm{CRF}=$ case report form; $\mathrm{MRI}=$ magnetic resonance imaging; $\mathrm{N}^{\prime}$ pathol $=$ neuropathology $; \mathrm{CRO}=$ contract research organization . 


\subsection{Neuropathology Reference and Subgrouping}

The main aim of the neuropathology reference and molecular grouping part is to provide a state-of-the-art molecular and histological sub-classification of post-pubertal medulloblastoma, to allow for the identification of new molecular targets, pathway modifiers, and resistance mechanisms, as well as to ensure suitable material for further analysis in other work packages $[16,60]$. The entire trial population will be subjected to central neuropathology assessment, with one European site and one Australian neuropathology site performing these central reviews. After exclusion of non-medulloblastomas, all cases will be molecularly analyzed by methylation-based classification employing the $850 \mathrm{~K}$ chip and detection of targetable mutations by next-generation panel sequencing (NGS) [80,81].

\subsection{Genotype-Based Subgrouping and Target Detection from Liquid Biopsies}

In this work package, we aim to identify and establish novel innovative biomarkers for response prediction and treatment monitoring to inform EORTC 1634-BTG/NOA-23 trial interpretation, but also future refined clinical trials. RNA sequencing data from fresh frozen tumor samples generated in this work package will be used for biomarker discovery, including the prediction of treatment response to SMO inhibition, identification of potential resistance mechanisms, and prediction of genotype-associated treatment toxicity. For this purpose, RNA sequencing data will be integrated with DNA methylation array data and panel sequencing data from primary tumor samples generated in the neuropathology subproject as well as circulating tumor DNA (ctDNA) data, imaging, and clinical outcome.

The work package will also test the feasibility of using ctDNA from CSF and blood for molecular subgrouping and treatment monitoring to assess minimal residual disease [82]. CSF and blood will be collected from all patients at baseline. Analyses of ctDNA using NGS gene panel sequencing will be used to track SHH-associated mutations in the CSF and blood. Patients with medulloblastoma predicted as $\mathrm{SHH}$ that harbor an $\mathrm{SHH}$-associated mutation will undergo liquid biopsies at three additional time points, following radiotherapy, following chemotherapy, and in case of relapse. The overall ambition is to identify novel, more precise predictive and minimal residual disease biomarkers for response prediction to radiotherapy, conventional chemotherapy, and SMO inhibition in post-pubertal SHH medulloblastoma patients to inform the next generation of trials.

\subsection{Imaging and Radiotherapy-Related Biomarkers}

Image analysis driven by deep learning enables new insights into tumor biology and how it is reflected in the imaging phenotype [83-85]. Within this work package, we will combine information derived from imaging data with clinical and genomic data from the other work packages towards two overarching goals: the first is to investigate the genotype-/imaging relationship in medulloblastoma. For this, we will associate clinical data and genomic data with imaging features through an automated pipeline, yielding non-invasive prediction models of the genotype and clinical variables from imaging data, as we already demonstrated for glioma [86]. We will also correlate-secondly-imaging and radiotherapy with clinical data to deepen the understanding of patterns of treatment failure $[87,88]$ and radiotherapy-associated neurotoxicity. A flexible data analysis platform will be developed that allows integrative analysis of imaging, clinical, and genomic data. Results from this subproject have the potential to assist clinical decision-making both for targeted therapies as well as radiotherapy. In addition, the potential to non-invasively observe genotype changes may help to shed further light on the development of treatment resistance.

In addition, we will also compare proton-based and photon-based radiotherapy in view of their toxicity on craniospinal axis function and on other systems including bone marrow function, neuro-cognitive function, hearing, endocrine function, and fertility. 


\subsection{Neurocognitive Function}

In post-pubertal patients with medulloblastoma, information on the mechanism of development of deficits in neurocognitive function (NCF), and thus insight into the potential future avenues for preventing treatment-related neurotoxicity, is widely lacking. NCF impairment after craniospinal irradiation is more severe in young patients with medulloblastoma, but is also prevalent in those irradiated as adults [89]. Impairments negatively affect daily life activities and psychosocial functioning [90]. In addition, NCF not only has independent prognostic significance on survival [91], but neurocognitive deterioration also indicates tumor progression before signs of disease recurrence are evident on MRI [92].

Since a combination of brain lesions, treatment side effects, and psychological distress is likely to contribute to neurocognitive dysfunction in an individually unpredictable way, it is most pragmatic to choose a core testing battery that gauges a broad range of neurocognitive functions. The test battery that meets this prerequisite in the best way has successfully been used in a number of multicenter clinical trials and has been recommended by the International Cognition and Cancer Task Force [93]. This clinical trial battery comprises the Hopkins Verbal Learning Test-Revised (HVLT-R) for total recall, delayed recall, and delayed recognition indexing verbal learning and memory [94]; the Trail Making Test (TMT part A and part B), which measures attention, visual-motor scanning speed, and executive function, and the Controlled Oral Word Association Test (COWA), which evaluates the spontaneous production of words under restricted search conditions [95]. In patients with medulloblastoma, cerebellar compromise due to tumor infiltration or treatment side effects may give rise to distinct deficits in executive functioning, linguistic processing, spatial cognition, and affect regulation. Therefore, NCF assessment in this trial will also include the cerebellar cognitive affective/Schmahmann syndrome scale [96].

The NCF tests will be administered by centrally trained and certified healthcare personnel—for example, a research nurse or neuropsychologist.

\subsection{Health-Related Quality of Life}

HRQoL is a highly relevant domain in the outcome of young adults with cancer $[97,98]$. Although data are scarce, previous studies have shown that HRQoL outcomes in adult medulloblastoma patients are poor directly postoperative, but improved during treatment up to 30 months post-treatment, after which scores deteriorate again [21,99]. In the 1634BTG study, HRQoL outcomes will be assessed longitudinally to determine the impact of the tumor and different treatment regimens on aspects of HRQoL and survivorship during the disease course. We will correlate health-related quality of life (HR-QoL) and neurocognitive function $(\mathrm{NCF})$ data at baseline and during the treatment course.

The primary HR-QoL scale that is considered relevant for this study is social functioning, as patients are typically younger adults with an active family and social life. The other scales from the EORTC QLQ-C30 and QLQ-BN20 [100] questionnaires will be considered exploratory in nature. Selected items from the survivorship questionnaire QLQ-SURV111 will also be used [101], including issues related to recurrence, mortgage/loans/insurance, job opportunities and life plans/goals, and relationships with friends and family. Mean HRQoL and survivorship scores over time, as well as mean changes in scores over time, will be evaluated. Relevant subgroup analyses (e.g., SHH subgroup vs. WNT subgroup vs. group 3 and group 4; or proton- vs. photon-based craniospinal radiotherapy) will be performed and HRQoL outcomes will be compared with data from the pediatric population in order to determine similarities in neurotoxicity.

\subsection{Fertility and Endocrine Function}

Radiotherapy and systemic therapy in medulloblastoma patients have a high risk of causing loss or damage of gonadal tissue or gametes or loss or reduction in sex hormones. These abnormalities may result in reproductive complications in survivors of medulloblastoma [102,103]. Potential and actual infertility affects the future quality of life 
of patients, leads to psychological distress, and is a predictor of stress in present and future relationships [104].

With the development of fertility preservation strategies and oncofertility care, which have been laid down in international guidelines, an increasing number of patients of reproductive age are being referred for fertility preservation and may be able to plan for a biological child after cancer treatment [105]. However, there are a number of barriers to delivering oncofertility care [106], including the lack of available reproductive information that is documented in clinical trials' protocols about the gonadotoxic and teratogenic risk of new treatment modalities and recommendations for oncofertility care [107].

Very limited gonadotoxic data are available for patients with medulloblastoma and patients taking SMO inhibitors [108]. As part of the EORTC 1634-BTG/NOA-23 study, protocol patients will therefore have an opportunity to consent to an additional fertility substudy. This prospective longitudinal fertility study will describe the uptake and utilization of oncofertility care as well as psychosocial and mental health-related issues surrounding cancer patients of reproductive age. Patients will complete a fertility questionnaire at diagnosis and 12 months, 36 months, and 60 months after the end of treatments. In sites suitable for more detailed substudies, female patients will be assessed for menstrual cycles, reproductive hormones, and antral follicle count measured on pelvic ultrasound scan. Male patients will be assessed for testicular volume, semen analysis, and reproductive hormones.

\subsection{Comparison of Data with Data from Pediatric Trials}

Important efficacy, safety, and translational endpoints from clinical data as well as biomaterial and imaging data raised in EORTC 1634-BTG/NOA-23 will be statistically compared to the pediatric and adolescent SIOP-PNET5-MB medulloblastoma trial (ClinicalTrials.gov: NCT02066220, 26 May 2020) [37]. Endpoints of EORTC 1634-BTG/NOA-23 and functional scores used within the study have been harmonized with PNET5.

\section{Summary and Outlook}

EORTC 1634-BTG/NOA-23 will be the first prospective randomized trial in postpubertal pediatric and adult patients with medulloblastoma worldwide. In view of novel combination therapies, it will, for the first time, use a targeted therapy, sonidegib, in combination with radio-chemotherapy in a randomized setting, based on evaluation of the genetic subtype of medulloblastoma, and will therefore be personalized. Its main objectives will be to investigate if there is increased efficacy in the SHH subgroup due to the addition of the SMO inhibitor, sonidegib, and to assess in the whole population whether a reduction in radiotherapy toxicity can be attained without compromising efficacy by using a lower dose of radiotherapy.

Translational projects including molecular subgrouping, biomarker design, MRIimaging evaluation, radiotherapy quality assurance, and evaluation of neuro-cognitive function, health-related quality of life, and fertility/endocrine function are closely connected to the trial. As a result of this, EORTC 1634-BTG/NOA-23 will improve the characterization of medulloblastoma in post-pubertal adolescents and adults through clinical, molecular, and imaging biomarkers. EORTC 1634-BTG/NOA-23 will thereby have a potentially high impact on relieving the burden of medulloblastoma in post-pubertal patients. Information gleaned from this study will ultimately help to decrease short- and long-term toxicity and thereby inform therapeutic teams on how to best reintegrate affected patients into their social and professional lives.

Both the EORTC 1634-BTG/NOA-23 trial and the connected translational work packages aim to support research that advances therapeutic approaches while providing the best possible outcome with the least toxicity for each individual patient. EORTC 1634BTG/NOA-23 will therefore generate a wealth of data that can be explored in view of future clinical-translational and basic science-translational development, not only in patients with medulloblastoma but also in other rare cancers. 
Author Contributions: Conceptualization, P.H., D.F., M.G.M., S.E.C., L.D., M.K., S.M.P., C.Z., R.-D.K., A.v.D., S.R., T.G., D.S.Z.; writing-original draft preparation, P.H., D.F., E.H. (Elizabeth Hovey), M.G.M., K.W.P., B.W., C.S., S.E.C., L.D., M.K., A.A., E.H. (Elke Hattingen), S.H., S.M.P., C.Z., R.-D.K., M.-P.S., R.T., R.E., A.v.D., F.S., S.R., A.S.B., E.F., E.P. (Estela Pineda), D.B., E.P. (Ellen Peeters), T.G., M.V., J.E.C.B., J.G., D.S.Z., M.P., W.W., M.W.; writing, review and editing, P.H., S.M.P., W.W., M.W.; visualization, P.H.; funding acquisition, P.H., E.H. (Elizabeth Hovey), K.W.P., B.W., S.E.C., M.K., S.M.P., C.Z., M.-P.S., R.T., A.v.D., E.P., J.E.C.B., J.G., D.S.Z., W.W., M.W. All authors have read and agreed to the published version of the manuscript.

Funding: This research is funded by Deutsche Krebshilfe, grant number 70113453; by Canteen Australia; by Cancer Australia, grant number 1165910; by the Dutch Cancer Society, grant number 2021-1/13555; by the French Ministry of Health, grant number PHRC-K20-179; by the Swiss Brain Tumor Foundation; by an internal grant of the EORTC Brain Tumor Group, and by an educational grant of Sun Pharmaceuticals Industries Ltd.

Institutional Review Board Statement: The Institutional Review Board Statement for this trial has been applied for. The study will be conducted according to the guidelines of the Declaration of Helsinki and will be approved by the Institutional Review Boards of the involved institutions.

Informed Consent Statement: Informed consent will be obtained from all subjects involved in the study.

Acknowledgments: We acknowledge the Association des Neuro-oncologues d'Expression Française (ANOCEF), Cooperative Trials Group for Neuro-Oncology Australia (COGNO), European Organization for Research and Treatment of Cancer (EORTC), EORTC Brain Tumor Group, NeuroOnkologische Arbeitsgemeinschaft in der Deutschen Krebsgesellschaft (NOA), and all national neuro-oncological societies, reference centers, and sites that participate in the trial that for their great support.

Conflicts of Interest: The academic funders and Sun Pharmaceuticals Industries Ltd. had no role in the design of the study and will have no role in the collection, analyses, or interpretation of data, in the writing of manuscripts, or in the decision to publish results. A.A. has received research funding from Merck and honoraria for advisory board participation from Bayer. A.S.B. has received honoraria for lectures, consultation, or advisory board participation from Roche Bristol-Meyers Squibb, Merck, Daiichi Sankyo, travel support from Roche, Amgen, and AbbVie, and research support from Daiichi Sankyo, Roche. B.W. has received honoraria for lectures, consultation, or advisory board participation from the following for-profit companies: Philips Healthcare. C.S. has received honoraria for lectures, consultation, or advisory board participation from the following for-profit companies: AbbVie, Bristol-Myers Squibb, HRA Pharma, medac, Roche. C.Z. has served on scientific advisory boards for Philips and Bayer Schering; serves as co-editor on the Advisory Board of Clinical Neuroradiology; has received speaker honoraria from Bayer-Schering and Philips; the institution has received research support and investigator fees for clinical studies from Biogen Idec, Quintiles, MSD Sharp \& Dome, Boehringer Ingelheim, Inventive Health Clinical UK Ltd., Advance Cor, Brainsgate, Pfizer, Bayer-Schering, Novartis, Roche, Servier, Penumbra, WCT GmbH, Syngis, SSS International Clinical Research, PPD Germany GmbH, Worldwide Clinical Trials Ltd., Phenox, Covidien, Actelion, Medivation, Medtronic, Harrison Clinical Research, Concentric, Pharmtrace, Reverse Medical Corp., Premier Research Germany Ltd., Surpass Medical Ltd., GlaxoSmithKline, AXON Neuroscience, Bristol-Myers Squibb, Genentech, Acandis, EISAI, NeuroRx, Italfarmaco, Bioclinica, MIAC, and IXICO. No patents issued and pending. Currently, he is the president of the German Society of Neuroradiology (DGNR). D.B. has received honoraria for lectures, consultation, or advisory board participation from the following for-profit companies: Novartis, TEVA, Lilly. The following for-profit companies have supported clinical trials: Novartis, TEVA, Lundbeck. D.S.Z. has received honoraria for lectures, consultation, or advisory board participation from the following for-profit companies: Bayer, Day One therapeutics, Amgen. E.F. has received honoraria for lectures, consultation, or advisory board participation from the following for-profit companies: karyopharm. E.H. (Elizabeth Hovey) has received honoraria for participation in advisory boards for Janssen, Merck. M.W. has received research grants from Abbvie, Adastra, Apogenix, Merck, Sharp \& Dohme (MSD), Merck (EMD), Novocure, and Quercis, and honoraria for lectures or advisory board participation or consulting from Abbvie, Adastra, Basilea, Bristol Meyer Squibb (BMS), Celgene, Medac, Merck, Sharp \& Dohme (MSD), Merck (EMD), Nerviano Medical Sciences, Novartis, Orbus, Philogen, Roche, Tocagen, and yMabs. M.P. has received honoraria for lectures, consultation, or advisory board 
participation from the following for-profit companies: Bayer, Bristol-Myers Squibb, Novartis, Gerson Lehrman Group (GLG), CMC Contrast, GlaxoSmithKline, Mundipharma, Roche, BMJ Journals, MedMedia, Astra Zeneca, AbbVie, Lilly, Medahead, Daiichi Sankyo, Sanofi, Merck Sharp \& Dome, Tocagen, Adastra. The following for-profit companies have supported clinical trials and contracted research conducted by MP with payments made to his institution: Böhringer-Ingelheim, BristolMyers Squibb, Roche, Daiichi Sankyo, Merck Sharp \& Dome, Novocure, GlaxoSmithKline, AbbVie. P.H. has received honoraria for lectures, consultation, or advisory board participation from the following for-profit companies: Antisense Pharma, Bristol-Myers Squibb, GlaxoSmithKline, Lilly, medac, Merck Sharp \& Dome, Nanotherm, Novartis, Novocure, Roche. The following for-profit companies have supported clinical trials and contracted research conducted by PH with payments made to his institution: Antisense Pharma. S.R. has received honoraria for DMSC or advisory board participation from the following for-profit companies: Bristol-Myers Squibb, Cellgene, Novartis, Roche. All other authors report no conflicts of interest.

\section{References}

1. Smoll, N.R. Relative survival of childhood and adult medulloblastomas and primitive neuroectodermal tumors (PNETs). Cancer 2012, 118, 1313-1322. [CrossRef]

2. Peris-Bonet, R.; Martinez-Garcia, C.; Lacour, B.; Petrovich, S.; Giner-Ripoll, B.; Navajas, A.; Steliarova-Foucher, E. Childhood central nervous system tumours-incidence and survival in Europe (1978-1997): Report from Automated Childhood Cancer Information System project. Eur. J. Cancer 2006, 42, 2064-2080. [CrossRef] [PubMed]

3. Smoll, N.R.; Drummond, K.J. The incidence of medulloblastomas and primitive neurectodermal tumours in adults and children. J. Clin. Neurosci. 2012, 19, 1541-1544. [CrossRef]

4. Kool, M.; Korshunov, A.; Remke, M.; Jones, D.T.; Schlanstein, M.; Northcott, P.A.; Cho, Y.J.; Koster, J.; Schouten-van Meeteren, A.; van Vuurden, D.; et al. Molecular subgroups of medulloblastoma: An international meta-analysis of transcriptome, genetic aberrations, and clinical data of WNT, SHH, Group 3, and Group 4 medulloblastomas. Acta Neuropathol. 2012, 123, 473-484. [CrossRef] [PubMed]

5. Chang, C.H.; Housepian, E.M.; Herbert, C., Jr. An operative staging system and a megavoltage radiotherapeutic technic for cerebellar medulloblastomas. Radiology 1969, 93, 1351-1359. [CrossRef]

6. Padovani, L.; Sunyach, M.P.; Perol, D.; Mercier, C.; Alapetite, C.; Haie-Meder, C.; Hoffstetter, S.; Muracciole, X.; Kerr, C.; Wagner, J.P.; et al. Common strategy for adult and pediatric medulloblastoma: A multicenter series of 253 adults. Int. J. Radiat. Oncol. Biol. Phys. 2007, 68, 433-440. [CrossRef]

7. Brandes, A.A.; Franceschi, E.; Tosoni, A.; Blatt, V.; Ermani, M. Long-term results of a prospective study on the treatment of medulloblastoma in adults. Cancer 2007, 110, 2035-2041. [CrossRef]

8. Miralbell, R.; Bieri, S.; Huguenin, P.; Feldges, A.; Morin, A.M.; Garcia, E.; Wagner, H.P.; Wacker, P.; von der Weid, N. Prognostic value of cerebrospinal fluid cytology in pediatric medulloblastoma. Swiss Pediatric Oncology Group. Ann. Oncol. 1999, 10, 239-241. [CrossRef]

9. Zeltzer, P.M.; Boyett, J.M.; Finlay, J.L.; Albright, A.L.; Rorke, L.B.; Milstein, J.M.; Allen, J.C.; Stevens, K.R.; Stanley, P.; Li, H.; et al. Metastasis stage, adjuvant treatment, and residual tumor are prognostic factors for medulloblastoma in children: Conclusions from the Children's Cancer Group 921 randomized phase III study. J. Clin. Oncol. 1999, 17, 832-845. [CrossRef]

10. Kool, M.; Korshunov, A.; Pfister, S.M. Update on molecular and genetic alterations in adult medulloblastoma. Memo 2012, 5, 228-232. [CrossRef] [PubMed]

11. Remke, M.; Hielscher, T.; Northcott, P.A.; Witt, H.; Ryzhova, M.; Wittmann, A.; Benner, A.; von Deimling, A.; Scheurlen, W.; Perry, A.; et al. Adult medulloblastoma comprises three major molecular variants. J. Clin. Oncol. 2011, 29, 2717-2723. [CrossRef] [PubMed]

12. Cavalli, F.M.G.; Remke, M.; Rampasek, L.; Peacock, J.; Shih, D.J.H.; Luu, B.; Garzia, L.; Torchia, J.; Nor, C.; Morrissy, A.S.; et al. Intertumoral Heterogeneity within Medulloblastoma Subgroups. Cancer Cell 2017, 31, 737-754.e6. [CrossRef] [PubMed]

13. Frost, P.J.; Laperriere, N.J.; Wong, C.S.; Milosevic, M.F.; Simpson, W.J.; Pintilie, M. Medulloblastoma in adults. Int. J. Radiat. Oncol. Biol. Phys. 1995, 32, 951-957. [CrossRef]

14. Becker, R.L.; Becker, A.D.; Sobel, D.F. Adult medulloblastoma: Review of 13 cases with emphasis on MRI. Neuroradiology 1995, 37, 104-108. [CrossRef]

15. Kool, M.; Jones, D.T.; Jager, N.; Northcott, P.A.; Pugh, T.J.; Hovestadt, V.; Piro, R.M.; Esparza, L.A.; Markant, S.L.; Remke, M.; et al. Genome sequencing of SHH medulloblastoma predicts genotype-related response to smoothened inhibition. Cancer Cell 2014, 25, 393-405. [CrossRef]

16. Franceschi, E.; Hofer, S.; Brandes, A.A.; Frappaz, D.; Kortmann, R.D.; Bromberg, J.; Dangouloff-Ros, V.; Boddaert, N.; Hattingen, E.; Wiestler, B.; et al. EANO-EURACAN clinical practice guideline for diagnosis, treatment, and follow-up of post-pubertal and adult patients with medulloblastoma. Lancet Oncol. 2019, 20, e715-e728. [CrossRef]

17. Packer, R.J.; Goldwein, J.; Nicholson, H.S.; Vezina, L.G.; Allen, J.C.; Ris, M.D.; Muraszko, K.; Rorke, L.B.; Wara, W.M.; Cohen, B.H.; et al. Treatment of children with medulloblastomas with reduced-dose craniospinal radiation therapy and adjuvant chemotherapy: A Children's Cancer Group Study. J. Clin. Oncol. 1999, 17, 2127-2136. [CrossRef] 
18. Taylor, R.E.; Bailey, C.C.; Robinson, K.; Weston, C.L.; Ellison, D.; Ironside, J.; Lucraft, H.; Gilbertson, R.; Tait, D.M.; Walker, D.A.; et al. Results of a randomized study of preradiation chemotherapy versus radiotherapy alone for nonmetastatic medulloblastoma: The International Society of Paediatric Oncology/United Kingdom Children's Cancer Study Group PNET-3 Study. J. Clin. Oncol. 2003, 21, 1581-1591. [CrossRef] [PubMed]

19. Ang, C.; Hauerstock, D.; Guiot, M.C.; Kasymjanova, G.; Roberge, D.; Kavan, P.; Muanza, T. Characteristics and outcomes of medulloblastoma in adults. Pediatr. Blood Cancer 2008, 51, 603-607. [CrossRef]

20. Frappaz, D.; Faure-Conter, C.; Bonneville Levard, A.; Barritault, M.; Meyronet, D.; Sunyach, M.P. Medulloblastomas in adolescents and adults-Can the pediatric experience be extrapolated? Neurochirurgie 2018, 67, 76-82. [CrossRef]

21. Beier, D.; Proescholdt, M.; Reinert, C.; Pietsch, T.; Jones, D.T.W.; Pfister, S.M.; Hattingen, E.; Seidel, C.; Dirven, L.; Luerding, R.; et al. Multicenter pilot study of radiochemotherapy as first-line treatment for adults with medulloblastoma (NOA-07). Neuro Oncol. 2018, 20, 400-410. [CrossRef] [PubMed]

22. Christopherson, K.M.; Rotondo, R.L.; Bradley, J.A.; Pincus, D.W.; Wynn, T.T.; Fort, J.A.; Morris, C.G.; Mendenhall, N.P.; Marcus, R.B., Jr.; Indelicato, D.J. Late toxicity following craniospinal radiation for early-stage medulloblastoma. Acta Oncol. 2014, 53, 471-480. [CrossRef]

23. Friedrich, C.; von Bueren, A.O.; von Hoff, K.; Kwiecien, R.; Pietsch, T.; Warmuth-Metz, M.; Hau, P.; Deinlein, F.; Kuehl, J.; Kortmann, R.D.; et al. Treatment of adult nonmetastatic medulloblastoma patients according to the paediatric HIT 2000 protocol: A prospective observational multicentre study. Eur. J. Cancer 2013, 49, 893-903. [CrossRef] [PubMed]

24. Packer, R.J.; Sutton, L.N.; Elterman, R.; Lange, B.; Goldwein, J.; Nicholson, H.S.; Mulne, L.; Boyett, J.; D’Angio, G.; WechslerJentzsch, K.; et al. Outcome for children with medulloblastoma treated with radiation and cisplatin, CCNU, and vincristine chemotherapy. J. Neurosurg. 1994, 81, 690-698. [CrossRef] [PubMed]

25. Kortmann, R.D.; Kuhl, J.; Timmermann, B.; Mittler, U.; Urban, C.; Budach, V.; Richter, E.; Willich, N.; Flentje, M.; Berthold, F.; et al. Postoperative neoadjuvant chemotherapy before radiotherapy as compared to immediate radiotherapy followed by maintenance chemotherapy in the treatment of medulloblastoma in childhood: Results of the German prospective randomized trial HIT ' 91. Int. J. Radiat. Oncol. Biol. Phys. 2000, 46, 269-279. [CrossRef]

26. Lannering, B.; Rutkowski, S.; Doz, F.; Pizer, B.; Gustafsson, G.; Navajas, A.; Massimino, M.; Reddingius, R.; Benesch, M.; Carrie, C.; et al. Hyperfractionated versus conventional radiotherapy followed by chemotherapy in standard-risk medulloblastoma: Results from the randomized multicenter HIT-SIOP PNET 4 trial. J. Clin. Oncol. 2012, 30, 3187-3193. [CrossRef]

27. Franceschi, E.; Bartolotti, M.; Paccapelo, A.; Marucci, G.; Agati, R.; Volpin, L.; Danieli, D.; Ghimenton, C.; Gardiman, M.P.; Sturiale, C.; et al. Adjuvant chemotherapy in adult medulloblastoma: Is it an option for average-risk patients? J. Neurooncol. 2016, 128, 235-240. [CrossRef]

28. Louis, D.N.; Perry, A.; Reifenberger, G.; von Deimling, A.; Figarella-Branger, D.; Cavenee, W.K.; Ohgaki, H.; Wiestler, O.D.; Kleihues, P.; Ellison, D.W. The 2016 World Health Organization Classification of Tumors of the Central Nervous System: A summary. Acta Neuropathol. 2016, 131, 803-820. [CrossRef]

29. Zhukova, N.; Ramaswamy, V.; Remke, M.; Pfaff, E.; Shih, D.J.; Martin, D.C.; Castelo-Branco, P.; Baskin, B.; Ray, P.N.; Bouffet, E.; et al. Subgroup-specific prognostic implications of TP53 mutation in medulloblastoma. J. Clin. Oncol. 2013, 31, $2927-2935$. [CrossRef] [PubMed]

30. Shih, D.J.; Northcott, P.A.; Remke, M.; Korshunov, A.; Ramaswamy, V.; Kool, M.; Luu, B.; Yao, Y.; Wang, X.; Dubuc, A.M.; et al. Cytogenetic prognostication within medulloblastoma subgroups. J. Clin. Oncol. 2014, 32, 886-896. [CrossRef] [PubMed]

31. Taylor, M.D.; Liu, L.; Raffel, C.; Hui, C.C.; Mainprize, T.G.; Zhang, X.; Agatep, R.; Chiappa, S.; Gao, L.; Lowrance, A.; et al. Mutations in SUFU predispose to medulloblastoma. Nat. Genet. 2002, 31, 306-310. [CrossRef] [PubMed]

32. Thompson, E.M.; Hielscher, T.; Bouffet, E.; Remke, M.; Luu, B.; Gururangan, S.; McLendon, R.E.; Bigner, D.D.; Lipp, E.S.; Perreault, S.; et al. Prognostic value of medulloblastoma extent of resection after accounting for molecular subgroup: A retrospective integrated clinical and molecular analysis. Lancet Oncol. 2016, 17, 484-495. [CrossRef]

33. Albright, A.L.; Wisoff, J.H.; Zeltzer, P.M.; Boyett, J.M.; Rorke, L.B.; Stanley, P. Effects of medulloblastoma resections on outcome in children: A report from the Children's Cancer Group. Neurosurgery 1996, 38, 265-271. [CrossRef]

34. Abacioglu, U.; Uzel, O.; Sengoz, M.; Turkan, S.; Ober, A. Medulloblastoma in adults: Treatment results and prognostic factors. Int. J. Radiat. Oncol. Biol. Phys. 2002, 54, 855-860. [CrossRef]

35. Taylor, R.E.; Bailey, C.C.; Robinson, K.J.; Weston, C.L.; Ellison, D.; Ironside, J.; Lucraft, H.; Gilbertson, R.; Tait, D.M.; Saran, F.; et al. Impact of radiotherapy parameters on outcome in the International Society of Paediatric Oncology/United Kingdom Children's Cancer Study Group PNET-3 study of preradiotherapy chemotherapy for M0-M1 medulloblastoma. Int. J. Radiat. Oncol. Biol. Phys. 2004, 58, 1184-1193. [CrossRef]

36. Carrie, C.; Lasset, C.; Alapetite, C.; Haie-Meder, C.; Hoffstetter, S.; Demaille, M.C.; Kerr, C.; Wagner, J.P.; Lagrange, J.L.; Maire, J.P.; et al. Multivariate analysis of prognostic factors in adult patients with medulloblastoma. Retrospective study of 156 patients. Cancer 1994, 74, 2352-2360. [CrossRef]

37. Dietzsch, S.; Braesigk, A.; Seidel, C.; Remmele, J.; Kitzing, R.; Schlender, T.; Mynarek, M.; Geismar, D.; Jablonska, K.; Schwarz, R.; et al. Pretreatment central quality control for craniospinal irradiation in non-metastatic medulloblastoma: First experiences of the German radiotherapy quality control panel in the SIOP PNET5 MB trial. Strahlenther. Onkol. 2020. [CrossRef] 
38. Kortmann, R.D.; Timmermann, B.; Kuhl, J.; Willich, N.; Flentje, M.; Meisner, C.; Bamberg, M. HIT '91 (prospective, co-operative study for the treatment of malignant brain tumors in childhood): Accuracy and acute toxicity of the irradiation of the craniospinal axis. Results of the quality assurance program. Strahlenther. Onkol. 1999, 175, 162-169. [CrossRef]

39. Ibrahim, N.Y.; Abdel Aal, H.H.; Abdel Kader, M.S.; Makaar, W.S.; Shaaban, A.H. Reducing late effects of radiotherapy in average risk medulloblastoma. Chin. Clin. Oncol. 2014, 3, 4. [CrossRef] [PubMed]

40. Massimino, M.; Sunyach, M.P.; Barretta, F.; Gandola, L.; Garegnani, A.; Pecori, E.; Spreafico, F.; Bonneville-Levard, A.; Meyronet, D.; Mottolese, C.; et al. Reduced-dose craniospinal irradiation is feasible for standard-risk adult medulloblastoma patients. $J$. Neurooncol. 2020, 148, 619-628. [CrossRef]

41. Packer, R.J.; Gajjar, A.; Vezina, G.; Rorke-Adams, L.; Burger, P.C.; Robertson, P.L.; Bayer, L.; LaFond, D.; Donahue, B.R.; Marymont, M.H.; et al. Phase III study of craniospinal radiation therapy followed by adjuvant chemotherapy for newly diagnosed averagerisk medulloblastoma. J. Clin. Oncol. 2006, 24, 4202-4208. [CrossRef]

42. Silber, J.H.; Radcliffe, J.; Peckham, V.; Perilongo, G.; Kishnani, P.; Fridman, M.; Goldwein, J.W.; Meadows, A.T. Whole-brain irradiation and decline in intelligence: The influence of dose and age on IQ score. J. Clin. Oncol. 1992, 10, 1390-1396. [CrossRef]

43. Mabbott, D.J.; Spiegler, B.J.; Greenberg, M.L.; Rutka, J.T.; Hyder, D.J.; Bouffet, E. Serial evaluation of academic and behavioral outcome after treatment with cranial radiation in childhood. J. Clin. Oncol. 2005, 23, 2256-2263. [CrossRef]

44. Moxon-Emre, I.; Bouffet, E.; Taylor, M.D.; Laperriere, N.; Scantlebury, N.; Law, N.; Spiegler, B.J.; Malkin, D.; Janzen, L.; Mabbott, D. Impact of craniospinal dose, boost volume, and neurologic complications on intellectual outcome in patients with medulloblastoma. J. Clin. Oncol. 2014, 32, 1760-1768. [CrossRef]

45. Ris, M.D.; Packer, R.; Goldwein, J.; Jones-Wallace, D.; Boyett, J.M. Intellectual outcome after reduced-dose radiation therapy plus adjuvant chemotherapy for medulloblastoma: A Children's Cancer Group study. J. Clin. Oncol. 2001, 19, 3470-3476. [CrossRef]

46. Palmer, S.L.; Armstrong, C.; Onar-Thomas, A.; Wu, S.; Wallace, D.; Bonner, M.J.; Schreiber, J.; Swain, M.; Chapieski, L.; Mabbott, D.; et al. Processing speed, attention, and working memory after treatment for medulloblastoma: An international, prospective, and longitudinal study. J. Clin. Oncol. 2013, 31, 3494-3500. [CrossRef] [PubMed]

47. King, A.A.; Seidel, K.; Di, C.; Leisenring, W.M.; Perkins, S.M.; Krull, K.R.; Sklar, C.A.; Green, D.M.; Armstrong, G.T.; Zeltzer, L.K.; et al. Long-term neurologic health and psychosocial function of adult survivors of childhood medulloblastoma/PNET: A report from the Childhood Cancer Survivor Study. Neuro Oncol. 2017, 19, 689-698. [CrossRef]

48. Kumar, N.; Miriyala, R.; Thakur, P.; Madan, R.; Salunke, P.; Yadav, B.; Gupta, A. Impact of acute hematological toxicity on treatment interruptions during cranio-spinal irradiation in medulloblastoma: A tertiary care institute experience. J. Neurooncol. 2017, 134, 309-315. [CrossRef] [PubMed]

49. Kamran, S.C.; Goldberg, S.I.; Kuhl, D.; Brainau, K.A.; Lawell, M.P.; Weyman, E.A.; Gallotto, S.L.; Hess, C.B.; Huang, M.S.; Friedmann, A.M.; et al. Quality of life in patients with proton-treated pediatric medulloblastoma: Results of a prospective assessment with 5-year follow-up. Cancer 2018, 124, 3390-3400. [CrossRef] [PubMed]

50. Brown, A.P.; Barney, C.L.; Grosshans, D.R.; McAleer, M.F.; de Groot, J.F.; Puduvalli, V.K.; Tucker, S.L.; Crawford, C.N.; Khan, M.; Khatua, S.; et al. Proton beam craniospinal irradiation reduces acute toxicity for adults with medulloblastoma. Int. J. Radiat. Oncol. Biol. Phys. 2013, 86, 277-284. [CrossRef] [PubMed]

51. Yock, T.I.; Yeap, B.Y.; Ebb, D.H.; Weyman, E.; Eaton, B.R.; Sherry, N.A.; Jones, R.M.; MacDonald, S.M.; Pulsifer, M.B.; Lavally, B.; et al. Long-term toxic effects of proton radiotherapy for paediatric medulloblastoma: A phase 2 single-arm study. Lancet Oncol. 2016, 17, 287-298. [CrossRef]

52. Eaton, B.R.; Esiashvili, N.; Kim, S.; Weyman, E.A.; Thornton, L.T.; Mazewski, C.; MacDonald, T.; Ebb, D.; MacDonald, S.M.; Tarbell, N.J.; et al. Clinical Outcomes Among Children With Standard-Risk Medulloblastoma Treated With Proton and Photon Radiation Therapy: A Comparison of Disease Control and Overall Survival. Int. J. Radiat. Oncol. Biol. Phys. 2016, 94, 133-138. [CrossRef] [PubMed]

53. Kocakaya, S.; Beier, C.P.; Beier, D. Chemotherapy increases long-term survival in patients with adult medulloblastoma-A literature-based meta-analysis. Neuro Oncol. 2016, 18, 408-416. [CrossRef] [PubMed]

54. Kann, B.H.; Lester-Coll, N.H.; Park, H.S.; Yeboa, D.N.; Kelly, J.R.; Baehring, J.M.; Becker, K.P.; Yu, J.B.; Bindra, R.S.; Roberts, K.B. Adjuvant chemotherapy and overall survival in adult medulloblastoma. Neuro Oncol. 2017, 19, 259-269. [CrossRef] [PubMed]

55. Brandes, A.A.; Ermani, M.; Amista, P.; Basso, U.; Vastola, F.; Gardiman, M.; Iuzzolino, P.; Turazzi, S.; Rotilio, A.; Volpin, L.; et al. The treatment of adults with medulloblastoma: A prospective study. Int. J. Radiat. Oncol. Biol. Phys. 2003, 57, 755-761. [CrossRef]

56. Herrlinger, U.; Steinbrecher, A.; Rieger, J.; Hau, P.; Kortmann, R.D.; Meyermann, R.; Schabet, M.; Bamberg, M.; Dichgans, J.; Bogdahn, U.; et al. Adult medulloblastoma: Prognostic factors and response to therapy at diagnosis and at relapse. J. Neurol. 2005, 252, 291-299. [CrossRef] [PubMed]

57. Franceschi, E.; Minichillo, S.; Mura, A.; Tosoni, A.; Mascarin, M.; Tomasello, C.; Bartolini, S.; Brandes, A.A. Adjuvant chemotherapy in average-risk adult medulloblastoma patients improves survival: A long term study. BMC Cancer 2020, 20, 755. [CrossRef]

58. Von Bueren, A.O.; Friedrich, C.; von Hoff, K.; Kwiecien, R.; Muller, K.; Pietsch, T.; Warmuth-Metz, M.; Hau, P.; Benesch, M.; Kuehl, J.; et al. Metastatic medulloblastoma in adults: Outcome of patients treated according to the HIT2000 protocol. Eur. J. Cancer 2015, 51, 2434-2443. [CrossRef]

59. Pak, E.; MacKenzie, E.L.; Zhao, X.; Pazyra-Murphy, M.F.; Park, P.M.C.; Wu, L.; Shaw, D.L.; Addleson, E.C.; Cayer, S.S.; Lopez, B.G.; et al. A large-scale drug screen identifies selective inhibitors of class I HDACs as a potential therapeutic option for SHH medulloblastoma. Neuro Oncol. 2019, 21, 1150-1163. [CrossRef] 
60. Northcott, P.A.; Robinson, G.W.; Kratz, C.P.; Mabbott, D.J.; Pomeroy, S.L.; Clifford, S.C.; Rutkowski, S.; Ellison, D.W.; Malkin, D.; Taylor, M.D.; et al. Medulloblastoma. Nat. Rev. Dis. Prim. 2019, 5, 11. [CrossRef]

61. Thompson, E.M.; Ashley, D.; Landi, D. Current medulloblastoma subgroup specific clinical trials. Transl. Pediatr. 2020, 9, 157-162. [CrossRef]

62. Frappaz, D.; Barritault, M.; Montane, L.; Laigle-Donadey, F.; Chinot, O.; Le Rhun, E.; Bonneville-Levard, A.; Hottinger, A.F.; Meyronnet, D.; Bidaux, A.S.; et al. MEVITEM-A Phase I/II of vismodegib + temozolomide vs temozolomide in patients with recurrent/refractory medulloblastoma with Sonic Hedgehog pathway activation. Neuro Oncol. 2021. [CrossRef]

63. Rimkus, T.K.; Carpenter, R.L.; Qasem, S.; Chan, M.; Lo, H.W. Targeting the Sonic Hedgehog Signaling Pathway: Review of Smoothened and GLI Inhibitors. Cancers 2016, 8, 22. [CrossRef]

64. Samkari, A.; White, J.; Packer, R. SHH inhibitors for the treatment of medulloblastoma. Expert Rev. Neurother. 2015, 15, 763-770. [CrossRef] [PubMed]

65. Gajjar, A.; Stewart, C.F.; Ellison, D.W.; Kaste, S.; Kun, L.E.; Packer, R.J.; Goldman, S.; Chintagumpala, M.; Wallace, D.; Takebe, N.; et al. Phase I study of vismodegib in children with recurrent or refractory medulloblastoma: A pediatric brain tumor consortium study. Clin. Cancer Res. 2013, 19, 6305-6312. [CrossRef] [PubMed]

66. Robinson, G.W.; Orr, B.A.; Wu, G.; Gururangan, S.; Lin, T.; Qaddoumi, I.; Packer, R.J.; Goldman, S.; Prados, M.D.; Desjardins, A.; et al. Vismodegib Exerts Targeted Efficacy Against Recurrent Sonic Hedgehog-Subgroup Medulloblastoma: Results From Phase II Pediatric Brain Tumor Consortium Studies PBTC-025B and PBTC-032. J. Clin. Oncol. 2015, 33, 2646-2654. [CrossRef]

67. Shou, Y.; Robinson, D.M.; Amakye, D.D.; Rose, K.L.; Cho, Y.J.; Ligon, K.L.; Sharp, T.; Haider, A.S.; Bandaru, R.; Ando, Y.; et al. A five-gene hedgehog signature developed as a patient preselection tool for hedgehog inhibitor therapy in medulloblastoma. Clin. Cancer Res. 2015, 21, 585-593. [CrossRef] [PubMed]

68. Rodon, J.; Tawbi, H.A.; Thomas, A.L.; Stoller, R.G.; Turtschi, C.P.; Baselga, J.; Sarantopoulos, J.; Mahalingam, D.; Shou, Y.; Moles, M.A.; et al. A phase I, multicenter, open-label, first-in-human, dose-escalation study of the oral smoothened inhibitor Sonidegib (LDE225) in patients with advanced solid tumors. Clin. Cancer Res. 2014, 20, 1900-1909. [CrossRef]

69. Kieran, M.W.; Chisholm, J.; Casanova, M.; Brandes, A.A.; Aerts, I.; Bouffet, E.; Bailey, S.; Leary, S.; MacDonald, T.J.; Mechinaud, F.; et al. Phase I study of oral sonidegib (LDE225) in pediatric brain and solid tumors and a phase II study in children and adults with relapsed medulloblastoma. Neuro Oncol. 2017, 19, 1542-1552. [CrossRef]

70. Robinson, G.W.; Kaste, S.C.; Chemaitilly, W.; Bowers, D.C.; Laughton, S.; Smith, A.; Gottardo, N.G.; Partap, S.; Bendel, A.; Wright, K.D.; et al. Irreversible growth plate fusions in children with medulloblastoma treated with a targeted hedgehog pathway inhibitor. Oncotarget 2017, 8, 69295-69302. [CrossRef]

71. Morrissy, A.S.; Garzia, L.; Shih, D.J.; Zuyderduyn, S.; Huang, X.; Skowron, P.; Remke, M.; Cavalli, F.M.; Ramaswamy, V.; Lindsay, P.E.; et al. Divergent clonal selection dominates medulloblastoma at recurrence. Nature 2016, 529, 351-357. [CrossRef]

72. Li, Y.; Song, Q.; Day, B.W. Phase I and phase II sonidegib and vismodegib clinical trials for the treatment of paediatric and adult MB patients: A systemic review and meta-analysis. Acta Neuropathol. Commun. 2019, 7, 123. [CrossRef] [PubMed]

73. Jain, S.; Song, R.; Xie, J. Sonidegib: Mechanism of action, pharmacology, and clinical utility for advanced basal cell carcinomas. Onco Targets Ther. 2017, 10, 1645-1653. [CrossRef]

74. Phoenix, T.N.; Patmore, D.M.; Boop, S.; Boulos, N.; Jacus, M.O.; Patel, Y.T.; Roussel, M.F.; Finkelstein, D.; Goumnerova, L.; Perreault, S.; et al. Medulloblastoma Genotype Dictates Blood Brain Barrier Phenotype. Cancer Cell 2016, 29, 508-522. [CrossRef]

75. Peng, J.; Zhou, H.; Tang, O.; Chang, K.; Wang, P.; Zeng, X.; Shen, Q.; Wu, J.; Xiao, Y.; Patel, S.H.; et al. Evaluation of RAPNO criteria in medulloblastoma and other leptomeningeal seeding tumors using MRI and clinical data. Neuro Oncol. 2020, 22, 1536-1544. [CrossRef] [PubMed]

76. Wang, Z.; Sun, H.; Yakisich, J.S. Overcoming the blood-brain barrier for chemotherapy: Limitations, challenges and rising problems. Anticancer Agents Med. Chem. 2014, 14, 1085-1093. [CrossRef] [PubMed]

77. Casey, D.; Demko, S.; Shord, S.; Zhao, H.; Chen, H.; He, K.; Putman, A.; Helms, W.; Keegan, P.; Pazdur, R. FDA Approval Summary: Sonidegib for Locally Advanced Basal Cell Carcinoma. Clin. Cancer Res. 2017, 23, 2377-2381. [CrossRef]

78. Atalar, B.; Ozsahin, M.; Call, J.; Napieralska, A.; Kamer, S.; Villa, S.; Erpolat, P.; Negretti, L.; Lassen-Ramshad, Y.; Onal, C.; et al. Treatment outcome and prognostic factors for adult patients with medulloblastoma: The Rare Cancer Network (RCN) experience. Radiother. Oncol. 2018, 127, 96-102. [CrossRef]

79. Oyharcabal-Bourden, V.; Kalifa, C.; Gentet, J.C.; Frappaz, D.; Edan, C.; Chastagner, P.; Sariban, E.; Pagnier, A.; Babin, A.; Pichon, F.; et al. Standard-risk medulloblastoma treated by adjuvant chemotherapy followed by reduced-dose craniospinal radiation therapy: A French Society of Pediatric Oncology Study. J. Clin. Oncol. 2005, 23, 4726-4734. [CrossRef]

80. Capper, D.; Jones, D.T.W.; Sill, M.; Hovestadt, V.; Schrimpf, D.; Sturm, D.; Koelsche, C.; Sahm, F.; Chavez, L.; Reuss, D.E.; et al. DNA methylation-based classification of central nervous system tumours. Nature 2018, 555, 469-474. [CrossRef]

81. Sahm, F.; Schrimpf, D.; Jones, D.T.; Meyer, J.; Kratz, A.; Reuss, D.; Capper, D.; Koelsche, C.; Korshunov, A.; Wiestler, B.; et al. Next-generation sequencing in routine brain tumor diagnostics enables an integrated diagnosis and identifies actionable targets. Acta Neuropathol. 2016, 131, 903-910. [CrossRef] [PubMed]

82. Escudero, L.; Llort, A.; Arias, A.; Diaz-Navarro, A.; Martinez-Ricarte, F.; Rubio-Perez, C.; Mayor, R.; Caratu, G.; Martinez-Saez, E.; Vazquez-Mendez, E.; et al. Circulating tumour DNA from the cerebrospinal fluid allows the characterisation and monitoring of medulloblastoma. Nat. Commun. 2020, 11, 5376. [CrossRef] 
83. Keil, V.C.; Warmuth-Metz, M.; Reh, C.; Enkirch, S.J.; Reinert, C.; Beier, D.; Jones, D.T.W.; Pietsch, T.; Schild, H.H.; Hattingen, E.; et al. Imaging Biomarkers for Adult Medulloblastomas: Genetic Entities May Be Identified by Their MR Imaging Radiophenotype. AJNR Am. J. Neuroradiol. 2017, 38, 1892-1898. [CrossRef] [PubMed]

84. Nadeem, M.W.; Ghamdi, M.A.A.; Hussain, M.; Khan, M.A.; Khan, K.M.; Almotiri, S.H.; Butt, S.A. Brain Tumor Analysis Empowered with Deep Learning: A Review, Taxonomy, and Future Challenges. Brain Sci. 2020, 10, 118. [CrossRef] [PubMed]

85. Chang, P.; Grinband, J.; Weinberg, B.D.; Bardis, M.; Khy, M.; Cadena, G.; Su, M.Y.; Cha, S.; Filippi, C.G.; Bota, D.; et al. DeepLearning Convolutional Neural Networks Accurately Classify Genetic Mutations in Gliomas. AJNR Am. J. Neuroradiol. 2018, 39, 1201-1207. [CrossRef] [PubMed]

86. Eichinger, P.; Alberts, E.; Delbridge, C.; Trebeschi, S.; Valentinitsch, A.; Bette, S.; Huber, T.; Gempt, J.; Meyer, B.; Schlegel, J.; et al. Diffusion tensor image features predict IDH genotype in newly diagnosed WHO grade II/III gliomas. Sci. Rep. 2017, 7, 13396. [CrossRef]

87. Metz, M.C.; Molina-Romero, M.; Lipkova, J.; Gempt, J.; Liesche-Starnecker, F.; Eichinger, P.; Grundl, L.; Menze, B.; Combs, S.E.; Zimmer, C.; et al. Predicting Glioblastoma Recurrence from Preoperative MR Scans Using Fractional-Anisotropy Maps with Free-Water Suppression. Cancers 2020, 12, 728. [CrossRef]

88. Lipkova, J.; Angelikopoulos, P.; Wu, S.; Alberts, E.; Wiestler, B.; Diehl, C.; Preibisch, C.; Pyka, T.; Combs, S.E.; Hadjidoukas, P.; et al. Personalized Radiotherapy Design for Glioblastoma: Integrating Mathematical Tumor Models, Multimodal Scans, and Bayesian Inference. IEEE Trans. Med. Imaging 2019, 38, 1875-1884. [CrossRef]

89. De, B.; Beal, K.; De Braganca, K.C.; Souweidane, M.M.; Dunkel, I.J.; Khakoo, Y.; Gilheeney, S.W.; DeAngelis, L.M.; Menzel, P.; Patel, S.H.; et al. Long-term outcomes of adult medulloblastoma patients treated with radiotherapy. J. Neurooncol. 2018, 136, 95-104. [CrossRef]

90. Taphoorn, M.J.; Klein, M. Cognitive deficits in adult patients with brain tumours. Lancet Neurol. 2004, 3, 159-168. [CrossRef]

91. Klein, M.; Postma, T.J.; Taphoorn, M.J.; Aaronson, N.K.; Vandertop, W.P.; Muller, M.; van der Ploeg, H.M.; Heimans, J.J. The prognostic value of cognitive functioning in the survival of patients with high-grade glioma. Neurology 2003, 61, 1796-1798. [CrossRef] [PubMed]

92. Armstrong, C.L.; Goldstein, B.; Shera, D.; Ledakis, G.E.; Tallent, E.M. The predictive value of longitudinal neuropsychologic assessment in the early detection of brain tumor recurrence. Cancer 2003, 97, 649-656. [CrossRef] [PubMed]

93. Wefel, J.S.; Vardy, J.; Ahles, T.; Schagen, S.B. International Cognition and Cancer Task Force recommendations to harmonise studies of cognitive function in patients with cancer. Lancet Oncol. 2011, 12, 703-708. [CrossRef]

94. Shapiro, A.M.; Benedict, R.H.; Schretlen, D.; Brandt, J. Construct and concurrent validity of the Hopkins Verbal Learning Test-revised. Clin. Neuropsychol. 1999, 13, 348-358. [CrossRef]

95. Ehrenstein, W.H.; Heister, G.; Cohen, R. Trail Making Test and visual search. Arch. Psychiatr. Nervenkr. 1982, $231,333-338$. [CrossRef]

96. Hoche, F.; Guell, X.; Vangel, M.G.; Sherman, J.C.; Schmahmann, J.D. The cerebellar cognitive affective/Schmahmann syndrome scale. Brain 2018, 141, 248-270. [CrossRef]

97. Monteiro, S.; Torres, A.; Morgadinho, R.; Pereira, A. Psychosocial outcomes in young adults with cancer: Emotional distress, quality of life and personal growth. Arch. Psychiatr. Nurs. 2013, 27, 299-305. [CrossRef]

98. Sodergren, S.C.; Husson, O.; Robinson, J.; Rohde, G.E.; Tomaszewska, I.M.; Vivat, B.; Dyar, R.; Darlington, A.S.; Group, E.Q.o.L. Systematic review of the health-related quality of life issues facing adolescents and young adults with cancer. Qual. Life Res. 2017, 26, 1659-1672. [CrossRef]

99. Dirven, L.; Luerding, R.; Beier, D.; Bumes, E.; Reinert, C.; Seidel, C.; Bonsanto, M.M.; Bremer, M.; Rieken, S.; Combs, S.E.; et al. Neurocognitive functioning and health-related quality of life in adult medulloblastoma patients: Long-term outcomes of the NOA-07 study. J. Neurooncol. 2020, 148, 117-130. [CrossRef]

100. Aaronson, N.K.; Ahmedzai, S.; Bergman, B.; Bullinger, M.; Cull, A.; Duez, N.J.; Filiberti, A.; Flechtner, H.; Fleishman, S.B.; de Haes, J.C.; et al. The European Organization for Research and Treatment of Cancer QLQ-C30: A quality-of-life instrument for use in international clinical trials in oncology. J. Natl. Cancer Inst. 1993, 85, 365-376. [CrossRef]

101. Van Leeuwen, M.; Husson, O.; Alberti, P.; Arraras, J.I.; Chinot, O.L.; Costantini, A.; Darlington, A.S.; Dirven, L.; Eichler, M.; Hammerlid, E.B.; et al. Understanding the quality of life (QOL) issues in survivors of cancer: Towards the development of an EORTC QOL cancer survivorship questionnaire. Health Qual. Life Outcomes 2018, 16, 114. [CrossRef] [PubMed]

102. Balachandar, S.; Dunkel, I.J.; Khakoo, Y.; Wolden, S.; Allen, J.; Sklar, C.A. Ovarian function in survivors of childhood medulloblastoma: Impact of reduced dose craniospinal irradiation and high-dose chemotherapy with autologous stem cell rescue. Pediatr. Blood Cancer 2015, 62, 317-321. [CrossRef]

103. Cuny, A.; Trivin, C.; Brailly-Tabard, S.; Adan, L.; Zerah, M.; Sainte-Rose, C.; Alapetite, C.; Brugieres, L.; Habrand, J.L.; Doz, F.; et al. Inhibin B and anti-Mullerian hormone as markers of gonadal function after treatment for medulloblastoma or posterior fossa ependymoma during childhood. J. Pediatr. 2011, 158, 1016-1022.e1. [CrossRef] [PubMed]

104. Logan, S.; Perz, J.; Ussher, J.M.; Peate, M.; Anazodo, A. Systematic review of fertility-related psychological distress in cancer patients: Informing on an improved model of care. Psychooncology 2019, 28, 22-30. [CrossRef]

105. Anazodo, A.; Ataman-Millhouse, L.; Jayasinghe, Y.; Woodruff, T.K. Oncofertility-An emerging discipline rather than a special consideration. Pediatr. Blood Cancer 2018, 65, e27297. [CrossRef] [PubMed] 
106. Logan, S.; Perz, J.; Ussher, J.; Peate, M.; Anazodo, A. Clinician provision of oncofertility support in cancer patients of a reproductive age: A systematic review. Psychooncology 2018, 27, 748-756. [CrossRef]

107. Dauti, A.; Gerstl, B.; Chong, S.; Chisholm, O.; Anazodo, A. Improvements in Clinical Trials Information Will Improve the Reproductive Health and Fertility of Cancer Patients. J. Adolesc. Young Adult Oncol. 2017, 6, 235-269. [CrossRef]

108. Volckmar, X.; Vallejo, M.; Bertoldo, M.J.; Nguyen, Q.N.; Handelsman, D.J.; Chisholm, O.; Anazodo, A. Oncofertility Information Available for Recently Approved Novel Non Cytotoxic and Immunotherapy Oncology Drugs. Clin. Pharmacol. Ther. 2021. [CrossRef] [PubMed] 